\title{
Early age and hardened performance of cement pastes combining mineral additions
}

\author{
Gonzalo Barluenga , Irene Palomar, Javier Puentes \\ Departamento de Arquitectura. Escuela Técnica Superior de Arquitectura y Geodesia. \\ Universidad de Alcalá. C. Santa Úrsula, 8. Alcalá de Henares-28801, Madrid, Spain. \\ Phone: +34918839239.
}

Fax: +34918839276.

E-mail: gonzalo.barluenga@uah.es

\section{ABSTRACT}

To asses the influence of mineral additions (MA) at early age and on hardened performance of fluid cement based pastes, an experimental program was carried out. The design of the mixtures correspond to paste compositions used in self compacting concretes of moderated strength, as those employed for architectural applications. Two types of fillers (limestone and quartzite) have been used to substitute $50 \%$ of cement in a reference paste, with and without a high range water reducing admixture (HRWRA). Then, three active MA (microsilica, nanosilica and metakaolin) were combined. A physical and mechanical characterization in the hardened state showed that the inclusion of MA to a cement-filler mixture can moderately improve the hardened performance of the pastes. Air and water cured samples were tested in order to evaluate the influence of curing conditions.

At early ages (24 hours), in-situ temperature and ultrasonic pulse velocity (UPV) were monitored on samples with limestone filler, combined with the three active MA, to study the reaction process and microstructure development, respectively. The reaction degree of the samples under study during the first 24 hours was related to the microstructure development. Evaporation, drying shrinkage and cracking at early age were also monitored, considering an air flow of $3 \mathrm{~m} / \mathrm{s}$ on the exposed sample surface. Some relations were described linking cracking risks at early ages with the chemical and physical phenomena involved at early age microstructure evolution.

Cement paste; Mineral additions; Early age properties; Monitoring; UPV; Drying Shrinkage; Cracking

\section{Introduction}

Mineral additions (MA) have become an essential part of contemporary cement based materials and are considered to be one of the main components of the mixtures, together with cement, water, admixtures and aggregates [1,2]. The use of MA in cement based materials can be explained considering different material design strategies, among which, the most important are:

a. Cement substitution. It produces cheaper compounds, because MA with lower energy consumption are used, substituting a proportion of cement. As a result, the material generates a lower ecological impact due to the reduction of embodied $\mathrm{CO}_{2}$. However, mechanical performance achieved is limited and, under certain conditions, durability can be compromised.

b. Performance improvement, mainly mechanical, in the hardened state. High performance and high strength materials can be obtained. Reactive MA are used 
in order to modify cement paste microstructure. Physical and mechanical properties of the mixtures, such as permeability or strength, can be improved. On the other hand, an increase of heat production and a drop of $\mathrm{pH}$ can occur, because additions react with portlandite from hydrated cement, due to their hydraulic or pozzolanic ability, producing calcium silicate hydrates (CSH).

c. Increase of volume paste. It is used to obtain self compacting mixtures. The easiness of material placement can also be considered as a source of energy and ecological impact reduction, with a hardened performance similar to conventional mixtures. Large amounts of MA, up to $100 \%$ of cement weight, as industrial by-products or natural fillers, are commonly used.

In all cases, the mixture composition and the amount of MA is determined by a compromise among the required properties of the material at the different stages of the development process.

According to the material microstructure and performance during time, the evolution of cement based materials can be divided in four different stages: mixing and fresh state, early ages (corresponding to setting and initial hardening, up to 24 first hours after mixing), short term hardened state and long term.

A performed-based approach to the subject has been traditionally used, considering that the material performance at any stage depends on the proper development at the previous ones. The main technological features of the material performance are well defined in three of the four stages: workability in the fresh state, mechanical properties in short term hardened state and durability in the long term.

From this approach, early age cement based materials have usually been considered as a transitory state between fresh and hardened state. Most of the research has focused on the setting process and the curing conditions, considering two limits associated to technological performance: initial setting time, corresponding to the handling limit of fresh mixture, and final setting time, defining the moment when the material can be considered hardened.

Hardened performance (short and long term) depends on the microstructural development during early ages, as early age is a former stage in the material evolution [3]. As a result, a new approach considers cement based materials evolution as a timedependent sequential process and, therefore, material development at early ages is a key point of the process, because it enables the material performance in the following stages. A better understanding of early ages would allow for a better performance in the hardened state and the long term.

At early ages, a combination of chemical and physical processes take place in cement based materials, producing a change of the material microstructure, going from a liquid dispersion/solution to a pseudo-rigid solid. As a consequence, an evolution in material performance takes place. Two mechanisms have been described to be involved in the early age microstructure evolution [4]: grain connection (related to mechanical percolation threshold and elastic modulus) and pore filling (related to compressive strength).

Early age is considered to last the first 24 hours after casting. A different behaviour regarding fresh and hardened states has been described. Depending on the effectiveness of the process, the expected hardened performance will be achieved.

MA have been reported to modify the material evolution at early ages through two main mechanisms: facilitating the nucleation of hydrated cement products (fillers and nonactive MA [5-8]) and reacting with portlandite (active MA [8-17]), producing calcium silicate hydrates $(\mathrm{CSH})$ and aluminates $[9-11,18]$. Usually, MA are blended with 
cement constituting a binary mixture, although some research on ternary mixtures, combining a filler and an active addition have been described [18].

The environmental conditions during early ages can also modify the cement hydration and microstructure development. The chemical process requires certain temperature and humidity conditions which can be compromised by the heat and water interchanges that occur between the material and the environment. The effect of the environmental conditions at early ages involves changes on hydration kinetics and changes on porosity structure and shrinkage [19]. If the material has displacement constraints, early age cracking due to shrinkage can occur, producing a permanent damage and compromising durability [20-23].

A proper characterization of cement based materials at early ages requires experimental techniques different to the ones commonly used for fresh or hardened states. Monitoring several parameters, further than just determining setting times, has been proposed to assess the material evolution during early ages [19,24]. The chemical process can be estimated measuring the heat production, because cement hydration is an exothermal reaction $[5,25]$. Three experimental methods are used to determine heat production: isothermal and adiabatic tests and in-situ temperature measurement. Isothermal calorimetry measures the heat released by a small sample, liberated to the environment through a heat flux meter $[4,5,13]$, while adiabatic calorimetry evaluates the heat produced by an insulated sample through the sample temperature increase $[5,8,11,26$ 27]. In both techniques, a fine value of heat production rate is obtained, but the sample conditions are altered and cement hydration - a temperature dependent process [5] - can be modified.

In situ temperature records the internal temperature of a larger sample [26]. The main advantages are: the simplicity of the measurement; the sample conditions are not modified; and that the temperature variations are recorded at the same time as the hydration happens. On the other hand, the heat production rate can not be directly obtained, although a heat reaction degree, similar to that obtained in isothermal calorimetry [5] can be calculated, because the heat released is proportional to the temperature difference between the sample and the environment.

The changes on material microstructure can be estimated monitoring ultrasonic pulse velocity propagation (UPV) [4, 26-27]. UPV evolution depends on hydration process and can be related to physical changes and mechanical performance [29-31]. In this paper, an experimental program on early age cement based pastes , combining MA (fillers and active additions), is presented, monitoring key parameters, such as insitu temperature, UPV, shrinkage, evaporation and cracking, and a characterization in the hardened state of fluid cement based pastes was done. The design of fluid mixtures correspond to paste compositions used in self compacting concretes of moderated strength, as those employed for architectural applications.

The aim of this study was to identify the relations between the inclusion of different types and simple combinations of MA (binary and ternary mixtures) and the measured properties monitored on samples of cement based pastes. The study was designed in two stages to find: firstly, the relationships among early age properties evolution with regard to time, and secondly, between early age properties and hardened performance of the pastes under study.

The simultaneous monitoring of these parameters could allow a better understanding of the relations among the mechanisms involved in the hydration, microstructure evolution and cracking at early ages, since: temperature changes are related to hydration and chemical reaction processes; UPV is associated to microstructure development and drying shrinkage can be linked to early age cracking. 


\section{Experimental Program.}

\subsection{Materials}

In this study, ten different fluid cement pastes were tested. The compositions of the pastes are summarized in Table 1. A reference mixture, called REF, with a cement type CEM I 42,5 R (according to UNE-EN 197-1 [32]), supplied by Cementos Portland Valderrivas, and a water to cement ratio (w/c) of 0.36 was manufactured. In order to increase fluidity, the reference mixture was modified with a high range water reducing admixture (HRWRA), Glenium ${ }^{\circledR}$ ACE 425 manufactured by BASF, and it was designated REFG.

Then, two fillers were added to the REFG composition, substituting $50 \%$ of the cement: a limestone filler, Betocarb ${ }^{\circledR}$ P1-DA $(85 \pm 5 \%$ under $63 \mu)$, supplied by Omya Clariana SL, and a siliceous filler (105-115 $\mu$ ), manufactured by Gomez Vallejo S.A. Particle size distributions of both fillers are plotted in Figure 1. These mixtures are called CA and SI , respectively, and the water to fines content ratio (w/f) remained at 0.36 .

In a third stage, three active mineral additions were included to the mixtures, substituting part of the filler: a densified microsilica (MS), Meyco MS 610, and an amorphous nanosilica suspension (NS), Meyco MS 685, both supplied by BASF Construction Chemicals España S.L., and a metakaolin (MK), Optipozz ${ }^{\mathrm{TM}}$ (average diameter $1.35 \mu$ ), manufactured by Burgess Pigment Company and supplied by Omya Clariana S.L.

The chemical composition of the cement and the additions used, are presented in Table 2. The values correspond to nominal compositions, according to manufacturers, except the microsilica and the metakaolin, which were obtained through EDAX analyses. The water of the HRWRA and the nanosilica suspension was discounted from the liquid water added to the mixture and the w/f remained at 0.36 in all mixtures (Table 1). In all the mixtures except the cement paste without HRWRA, the spread measured using the flowing table test (standard UNE-EN 1015-3 [33]) was over $300 \mathrm{~mm}$.

\subsection{Experimental Methods}

Preparation of the compositions was done in two stages: dry components were mixed first and later, water and HRWRA were added. Due to the fineness of the limestone filler, and in order to obtain homogeneous mixtures, the mixing time was extended to 4 minutes in all cases.

\subsubsection{Hardened state}

A physical and mechanical characterization of the hardened pastes was carried out on standard 40 x 40 x $160 \mathrm{~mm}$ paste samples (UNE-EN 196-1:2005 [34]). The specimens were demolded at 24 hours and two curing conditions were considered. Water was applied on a set of samples and cured up to day 7, and another set was air cured at laboratory conditions $\left(22 \pm 2{ }^{\circ} \mathrm{C}\right.$ and $\left.60 \pm 10 \% \mathrm{RH}\right)$.

Apparent density $\left(\mathrm{D}_{\mathrm{ap}}\right)$ and open (accessible to water) porosity $\left(\mathrm{P}_{\mathrm{acc}}\right)$ were calculated at 7 days, weighing dry $\left(\mathrm{W}_{\mathrm{d}}\right)$, water saturated $\left(\mathrm{W}_{\text {sat }}\right)$ and submerged $\left(\mathrm{W}_{\text {sub }}\right)$ samples, using a hydrostatic balance, accordingly to Eq. 1 and Eq 2, respectively.

$$
D_{a p}=W_{d} /\left(W_{s a t}-W_{\text {sub }}\right)
$$




$$
P_{a c c}=\left(W_{s a t}-W_{d}\right) /\left(W_{\text {sat }}-W_{\text {sub }}\right)
$$

Compressive strength (according to UNE-EN 196-1:2005 [34]) and UPV were measured at 1, 7, 14 and 28 days on air cured (laboratory conditions) and water cured samples. In all cases, the water cured samples were taken out of the water 24 hours before testing.

\subsubsection{Early age temperature and UPV}

Temperature, UPV, free shrinkage and mass loss were monitored simultaneously on paste samples of the same batches during early ages (up to 24 hours).

The temperature of the sample was monitored with a TESTO AG 904 thermometer, placed inside the sample and connected to a computer. The samples were cast in a plastic mould of $300 \times 150 \times 80 \mathrm{~mm}$, and open to the environment air (laboratory conditions of $25-26^{\circ} \mathrm{C}$ and $50-55 \% \mathrm{RH}$ ).

UPV was monitored on samples cast in a plastic mould of $150 \times 100 \times 70 \mathrm{~mm}$ and with a PUNDIT Plus Ultrasonic device with $54 \mathrm{kHz}$ ultrasonic p-wave transducers in direct contact with the sample through perforations on the plastic moulds (distance between measurement heads of $140 \mathrm{~mm}$ ). The transducers were fixed to the mould using a hot melted adhesive that avoided position changes, or fresh paste leaks.

\subsubsection{Free shrinkage, mass loss and early age cracking}

Free shrinkage and mass loss during early ages, up to 24 hours, were monitored on the paste samples. The free shrinkage test was carried out both on samples sealed (covered with a plastic film) and on samples in contact with the environment where, the exposed surface of the sample was subject to an air flow of $3 \mathrm{~m} / \mathrm{s}$ during the first 6 hours. The samples mass loss, corresponding to the water evaporated from the exposed surface of the samples under the air flow, was monitored simultaneously, placing the shrinkage apparatus on a balance connected to a computer. The experimental setup for shrinkage and mass loss monitoring can be observed in Figure 3.

The shrinkage apparatus consisted on a steel tray with internal dimensions of $500 \times 100$ $\mathrm{x} 50 \mathrm{~mm}$ and an electronic LVDT connected to a digital register, which recorded displacement measurements $(0.01 \mathrm{~mm})$ every 10 minutes during the first 24 hours. Further descriptions have previously been published [23].

Early age cracking potential was measured using a double restrained slab test. The test setup (Figure 4) consisted of a steel tray with internal dimensions of $390 \times 390 \times 40$ $\mathrm{mm}$. To the base of the tray, galvanized steel $U$ shaped pieces $(30 \mathrm{~mm}$ width, $30 \mathrm{~mm}$ wings, $200 \mathrm{~mm}$ length) were screwed, at $20 \mathrm{~mm}$ of the edge and remained inside the sample, acting as anchorages that restrained displacement in the horizontal plane (producing a bidirectional restraint).

The pastes were cast in the mold and subjected to an air flow of $3 \mathrm{~m} / \mathrm{s}$ during the first 6 hours, in order to evaporate all the water exuded from the exposed surface of the slab, maximizing the risk of cracking during early ages [21-23]. The samples were demolded after 24 hours and stored in laboratory conditions $\left(22 \pm 2{ }^{\circ} \mathrm{C}\right.$ and $\left.60 \pm 10 \% \mathrm{RH}\right)$ until crack measurement at 7 days, allowing free shrinkage of the samples. This time period was selected due to the difficulty to measure all the cracks when the slab surface was still wet, although the main cracks were clearly visible after a few hours. As the slabs were demolded at 24 hours, the double displacement restrain system did only apply during this period. Crack length and width were measured using a ruler and a comparison scale respectively. 


\section{Experimental results and analysis}

The experimental program assessed the fresh and hardened performance of the reference mixtures and those with MA. A characterization of physical (apparent density, open porosity) and mechanical properties (compressive strength and UPV at several ages) in the hardened state was managed on samples with limestone and siliceous fillers, combined with microsilica (MS), nanosilica (NS) and metakaolin (MK). At early ages, temperature, UPV, shrinkage, mass loss and cracking were analysed only on samples with limestone. Samples with siliceous filler were not tested at early ages, because siliceous filler does not significantly modify early age evolution of cement pastes, as has been described [5, 7].

\subsection{Hardened performance and mechanical characterization}

\subsubsection{Apparent density and open porosity}

Apparent density and open (water accessible) porosity at 7 days of the reference mixtures (with and without HRWRA) and those with MA (limestone and siliceous fillers combined with active MA) are summarised in Table 3. These parameters were obtained according to Eq. 1 and Eq. 2. Apparent density is very similar for all batches. The mixtures with filler showed a decrease of the apparent density compared to reference compositions, due to the lower density of the fillers with regard to cement and the increase of porosity. The inclusion of active MA slightly decreased density. The inclusion of MS and MK moderates the open porosity while the use of NS produced the opposite effect.

\subsubsection{Mechanical performance}

Table 4 summarises compressive strength and UPV at 28 days, considering both water and air curing. Air curing resulted in a significantly lower compressive strength, especially on the reference mixtures, when compared to water cured samples. Mixtures with siliceous filler also showed a decrease in strength, while the reduction was lower for samples with limestone filler. The mixture with limestone filler and NS slightly increased compressive strength when air curing was applied.

UPV at 28 days is also affected by the curing method applied. For all cases considered in this study, the samples cured in water showed larger values of UPV than the air cured ones.

The evolution of compressive strength and UPV at 1, 7, 14 and 28 days of the mixtures under study are plotted in Figures 4and 5, respectively. The continue lines correspond to logarithmic adjustments. Compressive strength of the reference mixtures, both with and without HRWRA, expectedly presented larger values (almost double) during the 1 to 28 days period, with regard to mixtures with $50 \%$ of filler substitution. The inclusion of active MA to the mixture with filler produced an improvement of 10-20\% on compressive strength. In fact, compressive strength reached at day 1 was between 30 and $50 \%$ of the values achieved at 28 days.

UPV evolution was different depending on the filler considered. The difference between the reference and limestone filler samples increased with time, while the difference decreased in the case of the siliceous samples. 


\subsection{Early age temperature monitoring and reaction degree}

\subsubsection{Early age temperature}

Temperature evolution, during early ages (up to 24 hours), is plotted in Figure 6. The laboratory conditions measured for each test is presented in Table 5.

The use of a HRWRA in the reference mixture (REFG) produced a delay on the temperature evolution, enlarging the induction period. Due to the constant environmental conditions and the heat and water interchanges between the sample and the environment, a decrease of maximum temperature occurred, with regard to the reference mixture without HRWRA (REF). However, the substitution of $50 \%$ of the cement by limestone filler (sample CA) shortened the delay, although the HRWRA to cement ratio was the same in both cases (REFG and CA). The maximum temperature of all the samples with limestone filler was clearly lower than the reference mixtures, because the amount of cement was $50 \%$. Mixtures with MS and NS produced thermal curves similar to the sample with limestone filler only, but the maximum temperature occurred sometime before and was lower than CA. This fact can be related to the pozzolanic ability of the micro and nanosilica. In the case of the mixture with Metakaolin, the curve was softer and the maximum temperature was lower, and it was delayed when compared to the other samples with limestone filler.

\subsubsection{Temperature evolution}

In all the mixtures, four stages can be defined in relation to the hydration process of the cement phases $[5,25]$. In a first stage, an early temperature peak and, afterwards, a slight decrease occurred, until a minimum value was reached. This initial stage is commonly known as induction period and the initial peak can be related to early ettringite formation. In a second stage, an accelerated increase of temperature was measured. Thirdly, a constant increase occurred until the maximum temperature was reached. In both stages, fast portlandite and CSH formation governed the heat production, conditioned by water and space availability and stopped by water consumption. Finally, a slow decrease of temperature took place. A shoulder after the maximum value can be observed, which corresponded to the calcium aluminates hydration [5]. This shoulder is larger in the mixture with Metakaolin because it provides more aluminates to the composition (Table 2).

\subsubsection{Reaction degree $\left(R_{d, 24}\right)$}

During the first 24 hours, the sample temperature was always higher than the room temperature $\left(25-26^{\circ} \mathrm{C}\right)$, whereby the heat-flow always went from the sample to the environment. As the heat released by the sample is proportional to the temperature difference $(\Delta \mathrm{T})$ during time, and the heat of the sample is produced due to the exothermal reactions of the hydration process, the hydration rate can be estimated as proportional to the integration of temperature difference. Accordingly, a reaction degree index $\left(R_{d, 24}\right)$ can be defined as the fraction of the heat released at any point during testing [5]. It must be noted that the released heat includes the heat accumulated by the sample during the temperature rise, although it is also measured when the temperature decreases. In this study, the heat released has been considered at 24 hours (Eq. 3):

$$
R_{d, 24}(t)=\int_{0}^{t} \Delta T / \int_{0}^{24 h} \Delta T
$$


Figure 7 presents the reaction degree of the paste samples during the first 24 hours after mixing, calculated according to Eq. 3. An S-shaped curve was obtained for all mixtures. The $\mathrm{R}_{\mathrm{d}, 24}$ parameter allows an easier comparison of the hydration evolution among the mixtures considered in the study, rather than in-situ temperature. From a preliminary analysis, it can be said that the delay of the maximum values of temperature (CAMC and REFG mixtures) indicates a lower reaction degree at the same age. REF paste reacted faster than the other samples, closely followed by CA pastes, with MS and NS and without MA. The main key-point thermal values are summarised in Table 5.

\subsection{UPV and microstructure evolution}

\subsubsection{UPV monitoring}

Figure 8 plots the UPV curves during the first 24 hours. As it happened in temperature measurements, the inclusion of a HWRA to the reference cement paste produced a delay in the curve. In both cases (REF and REFG mixtures), the UPV at 24 hours was around $3500 \mathrm{~m} / \mathrm{s}$. The inclusion of limestone filler (mixture CA) produced an UPV curve quite similar to the reference mixtures, although a jump can be observed at 8 hours (around $2000 \mathrm{~m} / \mathrm{s}$ ) and later, at 24 hours the UPV was around $3000 \mathrm{~m} / \mathrm{s}$. Samples with active MA presented UPV very similar values to the CA mixture, although no jump is observed.

\subsubsection{UPV evolution}

As it happened when temperature was considered, four different stages of UPV evolution can be defined in all the mixtures under study, which can be related to the microstructure evolution. A first stage is governed by an unstable period during the first 1-4 hours. The values obtained ranged from 1000 to $1600 \mathrm{~m} / \mathrm{s}$. It should be noted that the UPV in water is $1500 \mathrm{~m} / \mathrm{s}$, although the presence of entrained air and solid particles can modify wave propagation, producing UPV values on pastes smaller than $1500 \mathrm{~m} / \mathrm{s}$ [27].

In a second stage, a landing or plateau with UPV values around $1600 \mathrm{~m} / \mathrm{s}$ was observed in all samples. This phase lasted several hours (from one hour, in the case of MS, to 5 hours, when the reference paste with HRWRA was tested). In a third stage, an accelerated increase of the UPV was observed, that lasted until the inflection point was reached (UPV values around $2000-2500 \mathrm{~m} / \mathrm{s}$ and second derivative is zero). At the end, a stage characterized by a slow increase happened, leading later to stability.

Figure 9 relates UPV and temperature monitored on the samples during the first 24 hours. The maximum temperature value corresponded approximately to the inflection point calculated for UPV. UPV can also be related to the reaction degree index $\left(\mathrm{R}_{\mathrm{d}, 24}\right)$ defined in 3.2, and is plotted in Figure 10. A linear adjustment can be established for UPV over 1500-1600 m/s (second UPV stage) for all the samples under study, which corresponds to values of $\mathrm{R}_{\mathrm{d}, 24}$ above 0.01 to 0.05 , depending on the mixture composition. The reference mixture with HRWRA (REFG) showed a higher UPV at the same reaction degree than the reference mixture without HRWRA (REF). UPV values of samples with limestone filler were lower than reference mixtures in all cases. The main key-point UPV values are also summarised in Table 5. 


\subsection{Early age drying shrinkage and cracking}

Early age shrinkage of the mixtures was tested considering two conditions: covered with a plastic film and uncovered and subjected to an air flow of $3 \mathrm{~m} / \mathrm{s}$ during the first 6 hours.

The covered samples did not produce any shrinkage measurement. Considering that autogenous shrinkage is a volume change resulting when there is no moisture transfer to the surrounding environment, it can be assessed that the shrinkage apparatus used did not record autogenous shrinkage for the mixtures under study.

On the contrary, all the samples under the air flow shrank, reaching maximum values between 1.8 and $5 \mathrm{~mm} / \mathrm{m}$, as it can be observed in Figure 11. The laboratory conditions for each test are summarised in Table 5 present. As the shrinkage measured was related to air flow and, therefore, to water evaporation, it can be concluded that all the shrinkage measured on the samples tested was due to drying of the sample surface exposed to the air flow.

\subsubsection{Early age drying shrinkage evolution}

Drying shrinkage began from 1.5 to 3 hours and finished between 3-5 hours, depending on the mixture considered. Samples with active MA showed the maximum shrinkage, followed by reference mixtures. The mixture with only limestone filler registered the lowest drying shrinkage and the process began the latest. The reference mixture with HRWRA shrank 1.5 hours later than the reference mixture without admixtures. The main key-point shrinkage values are summarised in Table 5.

Regarding the shape of the shrinkage curves, four stages can be identified. In a first stage, the pastes are in a plastic state and there is no shrinkage. In a second step, the shrinkage began in a fast way until a knee point (inflection point) was reached, followed by a third stage of slower increase until early age shrinkage ended. Afterwards, the paste was in a hardened state and shrinkage was almost stopped. Accordingly to the different phases described, early age drying shrinkage occurred during stages 2 and 3 .

\subsubsection{Evaporation rate}

The mass loss of the shrinkage test samples subject to airflow was measured, placing the shrinkage apparatus on a balance connected to a computer. It was observed that shrinkage ended at 6 hours, when the air flow finished, remaining constant until 24 hours (end of test). The evaporation rate of the samples was calculated, considering the area of the exposed surface, and is plotted in Figure 12.

All the samples delayed the beginning of evaporation, as can be seen in Table 5 . Reference mixture without HRWRA and samples with only limestone filler began to evaporate approximately 1 hour after placing, while in reference with HRWRA samples and in those with active MA, evaporation was delayed approximately half an hour. The delay in the evaporation start corresponded to the initial bleeding time of the sample, which in turn depends on water movements and settlement of the fresh pastes. As the airflow produced the evaporation of the bleeding water when it appears and that no water was visible on the sample exposed surface, it can be assumed that the evaporation rate corresponded to the bleeding rate of each mixture. A linear adjustment was calculated with the evaporation measurements (Figure 12), in order to estimate an average evaporation rate (Table 5). The mixtures with only limestone filler and those with MS showed the lowest evaporation rate. 


\subsubsection{Early age drying shrinkage vs. Evaporation rate}

Shrinkage can be related to evaporation rate during shrinkage stages 2 and 3, as shown in Figure 13. A linear adjustment can be established during this period, as both parameters must be related [19]. The sample with MS presented the maximum slope of the curve (higher shrinkage with lower evaporation rate). Reference mixtures and those with NS and MK had very similar slope (values around 4.5-5) and the samples with only limestone filler produced the softer slope.

In all the cases, some evaporation occurred before shrinkage began (during the plastic state of the samples). According to this, it can be said that although drying shrinkage depends on water evaporation, the combination with another phenomenon must occur in the paste at early ages which produces shrinkage. This phenomenon corresponds to paste stiffening due to the microstructure development and the change from a plastic state (viscous behaviour) to a pseudo-rigid state (visco-elastic behaviour) [4]

\subsubsection{Early age drying shrinkage vs. Reaction degree $\left(R_{d, 24}\right)$}

Figure 14 plots early age drying shrinkage related to $R_{d, 24}$. In all cases, shrinkage began for $R_{d}$ between 0.02 and 0.05, while the hydration was still incipient. Most of the shrinkage happened during the first 4 hours, although the end occurred between 4 and 6 hours $\left(\mathrm{R}_{\mathrm{d}, 24}\right.$ values between 0.1 and 0.2$)$.

Reference mixtures (REF and REFG) shrank at a similar $\mathrm{R}_{\mathrm{d}, 24}$, although it corresponded to an hour of delay for samples with HRWRA when time was considered. This results confirms the affirmation that $R_{d, 24}$ is a better parameter than time alone for comparing with other early age parameters.

Samples with MS and MK had shrinkage and $\mathrm{R}_{\mathrm{d}, 24}$ values similar to reference mixture with HRWRA (REFG). Sample with NS needed higher $\mathrm{R}_{\mathrm{d}, 24}$ values although maximum shrinkage was similar to MS and MK. Again, the mixture with only limestone filler (CA) had a higher $\mathrm{R}_{\mathrm{d}, 24}$ at shrinkage start.

\subsubsection{Early age cracking}

Total early age cracked area measured on slab samples subjected to an air flow of $3 \mathrm{~m} / \mathrm{s}$ on the sample exposed surface are summarised in Table 5. Maximum measured crack lengths and cracking areas are compared to the reference mixture values in Figure 15. This test assesses the cracking sensitivity of the mixtures under study and, as a result, cracking risk can be estimated. Results obtained indicated that all studied batches cracked under the applied test conditions. The first cracks were clearly visible during the first ages (2-4 hours).

The use of a HRWRA (REFG) did not modify the samples cracked area, though the crack length was three times larger. Slabs with limestone filler only (CA) and with MS and NS noticeably reduced both parameters. On the contrary, the mixture with MK showed a double cracked area than the reference mixture.

Figure 16 shows the cracked surfaces of the samples after the test. The cracks were ink marked to obtain a visible cracking map of the exposed surface of the tested slabs. Reference mixture without admixtures (REF) presented one main crack, along the surface, from side to side. The sample with HRWRA (REFG) had a mapped cracking pattern, with several interconnected cracks crossing the surface. The mixtures with MA had a rather different cracking pattern, following the embedded restraints, as no cracks could be observed in the middle of the exposed surface. This change suggests that different cracking mechanisms could be involved. 
It can be assumed that the measured cracking is produced by the early age sample drying shrinkage (the test conditions, air flow and temperature, were the same in cracking and drying shrinkage tests). As early age shrinkage happened during the initial 1-6 hours, and after that until 24 hours, shrinkage remained practically constant, it can be said that cracking must occur during these very early ages, which corresponded to $R_{d}$ under 0,2 . Therefore, the cracking risk at early ages due to drying shrinkage was highest during the first 6 hours after mixing.

\section{Discussion}

\subsection{Reference mixtures. Influence of HRWRA}

The reference mixtures showed a very similar hardened performance in both cases (without admixtures, REF, and with HRWRA, REFG), so it can be said that the use of HRWRA did not significantly affect on the hardened properties.

In contrast, other differences in the fresh state were observed. The hydration process (temperature) and microstructure evolution (UPV) of the mixture REFG was delayed compared to REF. Although and considering the same reaction degree $\left(R_{d, 24}\right)$, the use of HRWRA on the cement paste produced a larger microstructure evolution and stiffness. Drying shrinkage was also delayed, and the total shrinkage at 6 hours was lower when the HRWRA was used. However, evaporation (mass loss) of the REFG mixture occurred before and was lower than REF, but it did not produce any negative effect on shrinkage and early age cracking was very similar in both cases. Therefore, the use of a HRWRA modified the hydration process and microstructure formation, delaying both, but did not increase cracking risks at early ages.

\subsection{Influence of limestone filler}

The substitution of $50 \%$ of cement by limestone filler (mixture CA) decreased the hardened performance of the paste when compared to reference mixtures. Compressive strength at 28 days was reduced to $50 \%$, open porosity was three times larger and stiffness (related to UPV) was also lower.

At early ages, the use of limestone filler accelerates the hydration process, when compared to the reference mixture with HRWRA, and the $\mathrm{R}_{\mathrm{d}, 24}$ evolved quite similar to the reference without HRWRA. However, UPV was lower at the same age and the shrinkage start was delayed 3 hours (like REFG mixture). Total shrinkage and early age evaporation were much lower for CA mixture than for the reference mixtures and the $\mathrm{R}_{\mathrm{d}, 24}$ in any shrinkage stage was double (Table 5). Consequently, early age cracking risk was quite lower.

\subsection{Influence of MA}

The inclusion of the active MA improved compressive strength around $20 \%$ regarding to $\mathrm{CA}$, while the apparent density was slightly lower. Stiffness remained quite similar, according to UPV measurements.

At early ages, the mixtures with MS and NS did not show significant changes neither on temperature plot nor UPV, regarding CA, and the linear correlation between $R_{\mathrm{d}, 24}$ and UPV remained much the same. Although shrinkage was much larger on samples with MS and NS, no increase on cracking risk was identified. The evaporation rates differ for 
both active additions: MS has values similar to CA, while NS was much larger.

Therefore, different evaporation rates produced almost the same shrinkage and cracking. This could be due to a different pore size distribution, because of the different particle size of both MA [15-16].

The mixture with MK showed differences at early ages compared to MS and NS, especially regarding hydration process and cracking risks. The aluminates content of MK can explain the change in the temperature curve, which produces a delay on the $\mathrm{R}_{\mathrm{d}, 24}$. Nevertheless, the microstructure development (related to UPV) with regard to $\mathrm{R}_{\mathrm{d}, 24}$ is quite similar to MS. Total shrinkage is also very similar to both MS and NS, although the beginning is slightly delayed. At the end, evaporation rate is the highest for MK, very close to NS. The consequence of the combination of both circumstances $\left(R_{d, 24}\right.$ delay and larger evaporation rate which produced larger drying shrinkage) can explain the increase of early age cracking risk when MK was used.

\subsection{Hydration and microstructural evolution}

A temporal sequence of the different stages defined through the monitoring of early age material parameters (in-situ temperature, UPV and shrinkage during the first 12 hours) is summarised in Figure 17. A relation among the parameters and defined stages can be established as:

- The beginning of the hydration process (marked by the minimum of temperature, stage 2) preceded the UPV landing (stage 2), during which shrinkage also starts (stage 2).

- Early age Shrinkage (stages 2 and 3) occurred during the acceleration period of the hydration (temperature accelerated rising, stage 2).

- The beginning of UPV increase (stage 3), which meant a consolidation of the hardened state of the pastes, occurred at the end of the measured shrinkage (end of stage 3).

An exception to these relations can be observed for the reference mixture with HRWRA, as temperature and UPV evolution was delayed but not shrinkage. This change explains the retardant effect of this type of admixtures.

When the hydration process, microstructure evolution and environmental effect are taken into account, the relations among these parameters can be enlarged: the hydration process produces the changes on the microstructure and, when certain environmental conditions apply, drying shrinkage can occur.

\subsection{Percolation threshold and shrinkage}

According to the experimental results obtained, drying shrinkage happened due to the combined effect of water evaporation and grain connection (which produced a mechanical percolation threshold), as far as none of them alone produced shrinkage:

a. When hydration happened without evaporation (shrinkage samples covered with a plastic film), no shrinkage was recorded.

b. During the induction period (initial temperature decrease, stage 1) evaporation was observed, but no shrinkage was measured.

The main part of early age shrinkage happened between 1.5 and 4 hours, when hydration had already begun (stage 2 of temperature curve). Nevertheless, water evaporation had started earlier. This means that all the water evaporated before shrinkage began produced a volume reduction of the sample in the plastic stage, but not measurable horizontal shrinkage. Therefore, a threshold on paste stiffness is necessary in order to mobilize shrinkage mechanisms (grain connection and mechanical 
percolation threshold), further than evaporation alone. Grain connection produces pore formation and water evaporation creates menisci, both necessary to produce shrinkage. As a consequence of the previous explanation, the percolation threshold (which means the change of the paste from a viscous liquid to a visco-elastic porous solid) can be identified to be the beginning of the shrinkage stage 2 . $R_{d, 24}$ of around. 0.02 has been identified to correspond to the mechanical percolation threshold of cement based pastes [4].

\subsection{Early age cracking risk related to microstructure evolution}

The greatest cracking risk due to early age drying shrinkage has also been identified to be the stage 2 of shrinkage. UPV around 1500-1600 m/s and the accelerated temperature increase (stage $2,<4$ hours) are also associated to early age cracking risk.

Mechanisms of early age cracking due to drying shrinkage could be explained from the relations among hydration, microstructure, evaporation and shrinkage described. At early ages, two main mechanisms have proved to affect the microstructure formation: grain connection (first few hours) and pore filling (till 24 hours) [4]. After the initial induction period of the fluid paste, the hydration products nucleate around the cement grains, until they are interconnected (percolation threshold and pore formation). As a consequence, the material behaves as a viscous-elastic porous solid and it is not plastic any more.

If during this early age, the paste is subjected to evaporation on the exposed surface, drying shrinkage would occur, due to the lack of water in the pores and menisci formation. When the displacement of the sample is restrained, tensile strength could be overcome and the specimen would crack. The evaporation would also inhibit pore filling (second mechanism involved in microstructure development) in the paste near the exposed surface, because water is essential to dissolve hydration products and to allow nucleation inside the pore. In the rest of the material, where pores are water filled, the microstructure evolution continues and stiffness increases, facilitating crack propagation due to stress concentrations at the crack tips.

\section{Conclusions}

An experimental program has been carried out on the effects of mineral additions (MA), using two fillers and three active additions (microsilica, nanosilica and metakaolin), on the early age and hardened performance of fluid pastes.

In the hardened state, the inclusion of filler to the reference samples reduced the apparent density due to the porosity increase. Samples tested showed lower strength when subject to air curing, although mixtures with limestone filler showed to be less sensitive to curing conditions. The addition of active MA moderately increased compressive strength, when compared to samples with filler only.

At early ages, temperature, ultrasonic pulse velocity (UPV), evaporation and shrinkage were monitored during the first 24 hours and cracking was measured in mixtures with limestone filler combined with the three active MA. Several stages on temperature, UPV and shrinkage were defined and some relations among them were established, which can be summarised as: 
- The reaction degree $\left(\mathrm{R}_{\mathrm{d}, 24}\right)$ calculated from in-situ temperature measurements can be correlated with the evolution of UPV at early ages, after the induction period. It has been observed that the increase of UPV corresponded to the acceleration of the hydration process.

- Drying shrinkage at early ages is related both to the microstructure development, due to the hydration process, and to the environmental effect which produces water evaporation.

- Shrinkage beginning corresponds to the change on the paste behaviour from fluid (viscous) to rigid (visco-elastic).

- For the mixtures considered in this study, the $\mathrm{R}_{\mathrm{d}, 24}$ at the shrinkage beginning was approximately 0.02 , when the hydration process is still incipient.

- Drying shrinkage ended before the first 6 hours after mixing. Therefore, all the strain that produced early age cracking corresponded to this stage: accelerated increase of the sample temperature and UPV around 1500-1600 m/s.

- The maximum cracking risk can be estimated to occur during this stage, when the reaction degree $\left(\mathrm{R}_{\mathrm{d}, 24}\right)$ is under 0.2.

- The use of limestone filler anticipates the temperature increase at early ages, which is related to the speed of the hydration process.

- The combination of filler and active MA increased the early age drying shrinkage, although only in the case of the mixture with metakaolin a larger cracking risk was identified. This could be related to the reaction of the aluminates present in its composition.

The results obtained on pastes can be useful to study the main mechanisms involved in early age and hardened behaviour of more complex multiphase systems, as mortar or concrete. Further research on other MA combinations and mixture proportions is needed in order to better understand the parameters involved in early age cracking risks, which can compromise long term performance and durability.

\section{Acknowledgements.}

The authors want to acknowledge the contribution on the samples preparation and testing of the students Alvaro Mozas and Hector Arenas, and the help of Esperanza Salvador on the EDAX analysis of the SIDI of UAM, as well as the language revision done by Isabel Salto Weis. We would also want to thank R. Tascón, G. Sánchez and I. Pajares for their technical support. Some of the components were supplied by BASF Construction Chemicals España S.L., Omya Clariana SL and Cementos Portland Valderribas.

Financial support for this research was provided by the grant CCG-08-UAH/MAT 4038, co-funded by University of Alcalá and the Comunidad de Madrid; PI3-2008-0499, funded by the Spanish Ministry of Science and Innovation, and the Research Program Geomateriales (S2009/Mat-1629), funded by the Comunidad de Madrid. 


\section{References.}

[1]. Aitcin PC (2000) Cements of yesterday and today Concrete of tomorrow. Cement and Concrete Research 30: 1349-1359

[2]. Lothenbach B, Scrivener K, Hooton RD (2011) Supplementary cementitious materials, Cement and Concrete Research 41 (12): 1244-1256

[3]. Bentz DP (2008) A review of early-age properties of cement-based materials. Cement and Concrete Research 38:196-204

[4]. Boumiz, CV, Tenoudj FC (1996) Mechanical Properties of Cement Pastes and Mortars at Early Ages - Evolution with Time and Degree of Hydration. Advanced Cement Based Materials 3:94-106

[5]. Poppe A-M, De Schutter G (2005) Cement hydration in the presence of high filler contents. Cement and Concrete Research 35:2290 - 2299

[6]. Ye G, Liu X, De Schutter G, Poppe A-M, Taerwe L (2007) Influence of limestone powder used as filler in SCC on hydration and microstructure of cement pastes. Cement and Concrete Composites 29:94-102

[7]. Ye G, Liu X, Poppe A M, De Schutter G, van Breugel K (2007) Numerical simulation of the hydration process and the development of microstructure of self-compacting cement paste containing limestone as filler. Materials and Structures 40:865-875

[8]. Kadri E H, Aggoun S, De Schutter G, Ezziane K (2010) Combined effect of chemical nature and fineness of mineral powders on Portland cement hydration. Materials and Structures 43:665-673

[9]. Siddique R, Klaus J (2009) Influence of metakaolin on the properties of mortar and concrete: A review. Applied Clay Science 43:392-400

[10]. Lagier F, Kurtis K E (2007) Influence of Portland cement composition on early age reactions with metakaolin. Cement and Concrete Research 37:1411-1417

[11]. Bai J, Wild S (2002) Investigation of the temperature change and heat evolution of mortar incorporating PFA and metakaolin. Cement and Concrete Composites 24:201-209

[12]. Kadri EH, Duval R (2009) Hydration heat kinetics of concrete with silica fume, Construction and Building Materials 23:3388-3392

[13]. Langan BW, Weng K, Ward M.A (2002) Effect of silica fume and fly ash on heat of hydration of Portland cement. Cement and Concrete Research 32:1045-1051

[14]. Shih J-Y, Chang T-P, Hsiao T-C (2006) Effect of nanosilica on characterization of Portland cement composite. Materials Science and Engineering A 424:266-274

[15]. Senff L, Hotza D, Repette W L, Ferreira V M. Labrincha J A (2010) Mortars with nano$\mathrm{SiO}_{2}$ and micro-SiO $\mathrm{S}_{2}$ investigated by experimental design. Construction and Building Materials 24:1432-1437

[16]. Sanchez F, Sobolev K (2010) Nanotechnology in concrete - A review. Construction and Building Materials 24:2060-2071

[17]. Gaitero JJ, Campillo I, Guerrero A (2008) Reduction of the calcium leaching rate of cement paste by addition of silica nanoparticles. Cement and Concrete Research 38:1112-1118

[18]. Snelson D G, Wild S, O'Farrell M (2008) Heat of hydration of Portland CementMetakaolin-Fly ash (PC-MK-PFA) blends. Cement and Concrete Research 38:832-840

[19]. Darquennes A, Khokhar MIA, Rozière E, Loukili A, Grondin F, Staquet S (2011) Early age deformations of concrete with high content of mineral additions. Construction and Building Materials 25:1836-1847

[20]. Holt E, Leivo M (2004) Cracking risks associated with early age shrinkage, Cement and Concrete Composites, 26 (5):521-530.

[21]. Uno P (1998) Plastic Shrinkage Cracking and Evaporation Formulas. ACI Materials Journal 95 (4):365-375.

[22]. Kraai PP (1985) A proposed test to determine the cracking potential due to drying shrinkage of concrete. Concrete Construction 9 (30):775-778

[23]. Barluenga G, Hernández-Olivares F (2007) Cracking control of concretes modified with short AR-glass fibers at early age: Experimental results on standard concrete and SCC. Cement and Concrete Research 37(12):1624-1638.

[24]. Desmet B, Atitung K C, Abril Sanchez M A, Vantomme J, Feys D, Robeyst N., Audenaert K, De Schutter G, Boel V, Heirman G, Cizer Ö, Vandewalle L, Van Gemert D (2011) Monitoring the early-age hydration of self-compacting concrete using ultrasonic p-wave transmission and isothermal calorimetry. Materials and Structures 44:1537-1558 
[25]. Hesse C, Goetz-Neunhoeffer F, Neubauer J (2011) A new approach in quantitative in-situ $\mathrm{XRD}$ of cement pastes: Correlation of heat flow curves with early hydration reactions, Cement and Concrete Research 41:123-128

[26]. Voigt T, Grosse C U, Sun Z, Shah S P, Reinhardt H-W (2005) Comparison of ultrasonic wave transmission and reflection measurements with $\mathrm{P}$ - and $\mathrm{S}$-waves on early age mortar and concrete. Materials and Structures 38 (8):729-738

[27]. Robeyst N, Gruyaert E, Grosse CU, De Belie N (2008) Monitoring the setting of concrete containing blast-furnace slag by measuring the ultrasonic p-wave velocity. Cement and Concrete Research 38:1169-1176.

[28]. UNE-EN 196-9 (2011) Methods of testing cement - Part 9: Heat of hydration - Semiadiabatic method. Spanish Organization for Standardization (AENOR)

[29]. Sant G, Dehadrai M, Bentz D, Lura P, Ferraris CF, Bullard JW, Weiss J (2009) Detecting the fluid- to- solid transition in cement pastes. Comparing experimental and numerical techniques, Concrete International - ACI Comittee 236: 53-58.

[30]. Ye G, Lura P, van Breugel K,. Fraaij ALA (2004) Study on the development of the microstructure in cement-based materials by means of numerical simulation and ultrasonic pulse velocity measurement. Cement and Concrete Composites 26 (5):491-497

[31]. Trtnik G, Turk G, Kavčič F, Bosiljkov V B (2008) Possibilities of using the ultrasonic wave transmission method to estimate initial setting time of cement paste, Cement and Concrete Research 38:1336-1342

[32]. UNE-EN 197-1 (2000) Cement - Part 1: Composition, specifications and conformity criteria for common cements. Spanish Organization for Standardization (AENOR)

[33]. UNE-EN 1015-3 (2000) Determination of consistence of fresh mortar (by flow table). Spanish Organization for Standardization (AENOR)

[34]. UNE-EN 196-1 (2005) Methods of testing cement - Part 1: Determination of strength Spanish Organization for Standardization (AENOR) 


\section{LIST OF FIGURES}

Fig. 1 Particle size distribution of mineral fillers

Fig. 2 Experimental setup for shrinkage and mass loss monitoring during early ages

Fig. 3 Steel mould and experimental setup of the double restrained slab early age cracking test

Fig. 4 Compressive strength of hardened samples with limestone (CA) and siliceous (SI) filler at 1, 7, 14 and 28 days. Results of Air cured and Water cured samples

Fig. 5 Ultrasonic Pulse Velocity (UPV) of hardened samples with limestone (CA) and siliceous (SI) filler at 1, 7, 14 and 28 days. Results of Air cured and Water cured samples

Fig. 6 Temperature during early ages in paste samples

Fig. 7 Reaction degree of the pastes under study (up to 24 hours)

Fig. 8 Ultrasonic pulse velocity (UPV) at early ages of paste samples

Fig. 9 UPV of fluid pastes related to in-situ temperature at early ages (up to 24 hours)

Fig. 10 Ultrasonic Pulse Velocity (UPV) of pastes at early ages related to reaction degree (R

Fig. 11 Early age drying shrinkage of paste samples with limestone filler with air flow (3 $\mathrm{m} / \mathrm{s}$ )

Fig. 12 Water evaporation on paste samples at early ages (first 6 hours after casting under 3 $\mathrm{m} / \mathrm{s}$ air flow)

Fig. 13 Drying shrinkage and Evaporation during early age shrinkage development (approx. 2-4 hours)

Fig. 14 Drying Shrinkage of pastes with related to reaction degree at very early ages

Fig. 15 Cracked area and maximum crack length measured on cracking test of limestone filler samples and reference pastes

Fig. 16 Cracked samples with limestone filler and reference pastes after slab cracking test (dimensions 40 x $40 \mathrm{~cm}$ ). From left to right and downwards: REF, REF-G, CA, CAMC, CAMS and CANS

Fig. 17 Evolution and temporal relationships among Keypoint early age parameters (temperature, UPV and shrinkage)

\section{LIST OF TABLES}

Table 1 Compositions of the fluid cement pastes under study (components in $\mathrm{g}$ )

Table 2 Nominal chemical compositions of sample components (in \% of weight)

Table 3 Physical properties of hardened samples (7 days)

Table 4 Mechanical properties of hardened samples (28 days)

Table 5 Key points of the early age parameters of the fluid cement pastes under study 
Table 1 Compositions of the fluid cement pastes under study (components in $\mathrm{g}$ )

\begin{tabular}{|c|c|c|c|c|c|c|c|c|c|c|}
\hline & REF & REF G & $\mathrm{CA}$ & $\begin{array}{l}\text { CAM } \\
\text { S }\end{array}$ & $\begin{array}{l}\text { CAN } \\
\text { S }\end{array}$ & $\begin{array}{c}\text { CAM } \\
\text { C }\end{array}$ & SI & SIMS & SINS & SIMC \\
\hline $\begin{array}{l}\text { Cement CEM I 42,5 } \\
\mathrm{R}\end{array}$ & 1700 & 1700 & 850 & 850 & 850 & 850 & 850 & 850 & 850 & 850 \\
\hline $\begin{array}{l}\text { Siliceous Filler } \\
(105 / 115)\end{array}$ & - & - & - & - & - & - & 850 & 765 & 807.5 & 807.5 \\
\hline $\begin{array}{l}\text { Limestone Filler } \\
\text { (Betocarb P1-DA) }\end{array}$ & - & - & 850 & 765 & 807.5 & 807.5 & - & - & - & - \\
\hline $\begin{array}{l}\text { Micro-silica } \\
\text { (MEYCO MS 610) }\end{array}$ & - & - & - & 85 & - & - & - & 85 & - & - \\
\hline $\begin{array}{l}\text { Nano-silica } \\
\text { (MEYCO MS 685) }\end{array}$ & - & - & - & - & 193 & - & - & - & 193 & - \\
\hline $\begin{array}{l}\text { Metakaolin (Burgess } \\
\text { Optipozz) }\end{array}$ & - & - & - & - & - & 42.5 & - & - & - & 42.5 \\
\hline Water $(*)$ & 607 & 581 & 594 & 594 & 443 & 594 & 594 & 594 & 443 & 594 \\
\hline $\begin{array}{l}\text { HRWRA (Glenium } \\
\text { ACE425) }\end{array}$ & - & 25.5 & 12.75 & 12.75 & 12.75 & 12.75 & $\begin{array}{c}12.7 \\
5\end{array}$ & 12.75 & 12.75 & 12.75 \\
\hline $\mathrm{w} / \mathrm{c}(* *)$ & 0.36 & 0.36 & 0.71 & 0.71 & 0.71 & 0.71 & 0.71 & 0.71 & 0.71 & 0.71 \\
\hline $\begin{array}{l}\text { w/fines (cement }+ \\
\text { additions) }(* *)\end{array}$ & 0.36 & 0.36 & 0.36 & 0.36 & 0.36 & 0.36 & 0.36 & 0.36 & 0.36 & 0.36 \\
\hline
\end{tabular}

(*) Liquid water added.

(**)The amount of water included in the components (HRWRA and Nano-silica) was also taken into account.

Table 2 Nominal chemical compositions of sample components (in \% of weight)

\begin{tabular}{|c|c|c|c|c|c|c|}
\hline Chemical analyses (\%) & $\begin{array}{l}C E M I \\
42.5 R\end{array}$ & Limestone & $\begin{array}{l}\text { Siliceous } \\
\quad \text { filler }\end{array}$ & Microsilica & Nanosilica & Metakaolin \\
\hline $\mathrm{SiO}_{2}$ & 19.45 & - & $>98.0$ & 97.47 & $22 \pm 1.5$ & 51.27 \\
\hline $\mathrm{Al}_{2} \mathrm{O}_{3}$ & 5.33 & - & $<0.8$ & & - & 44.22 \\
\hline $\mathrm{Fe}_{2} \mathrm{O}_{3}$ & 3.24 & $\leq 0.03$ & $<0.05$ & & - & 1.04 \\
\hline $\mathrm{CaO}$ & 63.86 & -- & $<0.1$ & 1.98 & - & - \\
\hline $\mathrm{MgO}$ & 1.97 & - & $<0.05$ & & - & 1.92 \\
\hline $\mathrm{SO}_{3}$ & 3.20 & 0.04 & & & - & - \\
\hline $\mathrm{Na}_{2} \mathrm{O}$ & 0.15 & - & $<0.06$ & & - & - \\
\hline $\mathrm{K}_{2} \mathrm{O}$ & 0.85 & - & $<0.4$ & 0.55 & - & - \\
\hline $\mathrm{H}_{2} \mathrm{O}$ & - & - & - & & $78 \pm 1.5$ & - \\
\hline $\mathrm{TiO}_{2}$ & - & - & - & & - & 1.56 \\
\hline $\mathrm{CaCO}_{3}$ & - & $\geq 98.5$ & - & & - & - \\
\hline $\mathrm{MgCO}_{3}$ & - & $\leq 0.8$ & - & & - & - \\
\hline Other & 1.85 & - & $<1.01$ & - & $<0.6$ & - \\
\hline
\end{tabular}


Table 3 Physical properties of hardened samples (at 7 days)

\begin{tabular}{ccccccccccc}
\hline & REF & REFG & CA & CAMS & CANS & CAMC & SI & SIMS & SINS & SIMC \\
\hline $\begin{array}{c}\text { Apparent density } \\
\left(\mathbf{g} / \mathrm{cm}^{3}\right)\end{array}$ & 2.036 & 2.067 & 1.957 & 1.937 & 1.920 & 1.940 & 2.004 & 1.978 & 1.974 & 1.978 \\
Open Porosity (\%) & 1.382 & 1.529 & 4.261 & 3.218 & 4.733 & 3.344 & 4.844 & 3.147 & 5.019 & 3.912
\end{tabular}

Table 4 Mechanical properties of hardened samples (28 days)

\begin{tabular}{l|cc|c|c}
\hline Mixture & \multicolumn{2}{|c|}{ Compressive Strength (MPa) } & \multicolumn{2}{c}{ UPV (m/s) } \\
\hline & Water cured & Air cured & Water cured & Air cured \\
\hline REF & 72.5 & 58 & 4128 & 3568 \\
REFG & 72.5 & 62 & 4072 & 3608 \\
CA & 34.5 & 33 & 3552 & 3216 \\
CAMS & 39 & 33 & 3408 & 3152 \\
CANS & 39.5 & 40.5 & 3528 & 3264 \\
CAMC & 41.5 & 37.5 & 3576 & 3248 \\
SI & 29 & 24 & 3720 & 3216 \\
SIMS & 34.5 & 29 & 3736 & 3384 \\
SINS & 36 & 32 & 3800 & 3512 \\
SIMC & 33.5 & 28 & 3768 & 3424 \\
\hline
\end{tabular}


Table 5 Key points of the early age parameters of the fluid cement pastes under study

\begin{tabular}{|c|c|c|c|c|c|c|}
\hline & REF & REF G & CA & CAMS & CANS & CAMC \\
\hline \multicolumn{7}{|l|}{ Temperature } \\
\hline Minimum $\left({ }^{\circ} \mathrm{C}\right)$ & 29.00 & 26.40 & 27.25 & 26.70 & 26.95 & 26.50 \\
\hline Minimum (minutes) & 60 & 200 & 140 & 90 & 70 & 100 \\
\hline Maximum $\left({ }^{\circ} \mathrm{C}\right)$ & 72.70 & 63.80 & 46.90 & 45.95 & 45.80 & 42.80 \\
\hline Maximum (minutes) & 370 & 630 & 440 & 420 & 420 & 520 \\
\hline Reaction degree (Max. temperature) & 0.33 & 0.32 & 0.39 & 0.38 & 0.38 & 0.39 \\
\hline \multicolumn{7}{|l|}{ UPV (m/s) } \\
\hline $\begin{array}{l}\text { Initial time (reachs } 1500-1600 \mathrm{~m} / \mathrm{s} \text { ) } \\
\text { (minutes) }\end{array}$ & 90 & 80 & 60 & 180 & 120 & 30 \\
\hline UPV at max. temperature $(\mathrm{m} / \mathrm{s})$ & 1983 & 2291 & 1958 & 1958 & 1850 & 2041 \\
\hline "Knee" point $(\mathrm{m} / \mathrm{s})$ & 2389 & 2734 & 2026 & 2171 & 2038 & 2247 \\
\hline Reaction degree (UPV Knee point) & 0.59 & 0.51 & 0.50 & 0.58 & 0.63 & 0.48 \\
\hline Laboratory conditions (temp $\left.\left({ }^{\circ} \mathrm{C}\right) / \mathrm{RH}(\%)\right)$ & $25 / 50$ & $25 / 52$ & $25 / 54$ & $25 / 55$ & $26 / 51,5$ & $25 / 50,5$ \\
\hline \multicolumn{7}{|l|}{ Drying Shrinkage (air flow $3 \mathrm{~m} / \mathrm{s}$ ) } \\
\hline $\begin{array}{l}\text { Horizontal shrinkage }(\mathrm{mm} / \mathrm{m}) \text { at "Knee" } \\
\text { point }\end{array}$ & 1.48 & 1.06 & 0.90 & 2.10 & 1.68 & 2.12 \\
\hline Horizontal shrinkage $(\mathrm{mm} / \mathrm{m})$ at 6 hours & 3.16 & 2.42 & 1.76 & 4.62 & 4.34 & 4.24 \\
\hline Maximum horizontal shrinkage $(\mathrm{mm} / \mathrm{m})$ & 3.18 & 2.42 & 1.76 & 4.62 & 4.36 & 4.26 \\
\hline Initial time (minutes/reaction degree) & $\begin{array}{c}100 \\
(0.02)\end{array}$ & $\begin{array}{c}130 \\
(0.02)\end{array}$ & $\begin{array}{c}170 \\
(0.05)\end{array}$ & $\begin{array}{c}120 \\
(0.03)\end{array}$ & $\begin{array}{c}120 \\
(0.03)\end{array}$ & $\begin{array}{c}150 \\
(0.03)\end{array}$ \\
\hline "Knee" point time (minutes (reaction & 130 & 200 & 210 & 150 & 160 & 200 \\
\hline degree)) & $(0.03)$ & $(0.03)$ & $(0.07)$ & $(0.04)$ & $(0.04)$ & $(0.04)$ \\
\hline Final time (minutes/reaction degree) & $240(0.1)$ & $\begin{array}{c}300 \\
(0.04)\end{array}$ & $350(0.2))$ & $\begin{array}{c}300 \\
(0.15)\end{array}$ & $\begin{array}{c}320 \\
(0.18)\end{array}$ & $\begin{array}{c}320 \\
(0.11)\end{array}$ \\
\hline \multicolumn{7}{|l|}{ Mass loss (air flow 6 hours) } \\
\hline Initial time & $50 \mathrm{~m}$ & $20 \mathrm{~m}$ & $1 \mathrm{~h}$ & $30 \mathrm{~m}$ & $20 \mathrm{~m}$ & $20 \mathrm{~m}$ \\
\hline Final time & $6 \mathrm{~h} 10 \mathrm{~m}$ & $6 \mathrm{~h}$ & $5 \mathrm{~h} 50 \mathrm{~m}$ & $6 \mathrm{~h}$ & $6 \mathrm{~h} 40 \mathrm{~m}$ & $6 \mathrm{~h} 10 \mathrm{~m}$ \\
\hline Measured Evaporation at 6 hours $\left(\mathrm{kg} / \mathrm{m}^{2}\right)$ & 2.26 & 2.00 & 1.30 & 1.36 & 2.48 & 2.58 \\
\hline Evaporation rate at 6 hours $\left(\mathrm{kg} / \mathrm{h} \mathrm{m}^{2}\right)$ & 0.45 & 0.35 & 0.24 & 0.20 & 0.43 & 0.45 \\
\hline Evaporation at Shrinkage "Knee" point & 0.76 & 0.98 & 1.00 & 0.62 & 1.28 & 1.54 \\
\hline Laboratory conditions $\left(\right.$ temp $\left.\left({ }^{\circ} \mathrm{C}\right) / \mathrm{RH}(\%)\right)$ & $21 / 70$ & $21 / 51$ & $21 / 59$ & $20 / 55$ & $20 / 60$ & $18 / 51$ \\
\hline
\end{tabular}

Slab cracking test $(400 \times 400 \mathrm{~mm})$

Total Cracked area $\left(\mathrm{mm}^{2} / \mathrm{m}^{2}\right)$ 
Fig. 1 Particle size distribution of mineral fillers $(\mu \mathrm{m})$

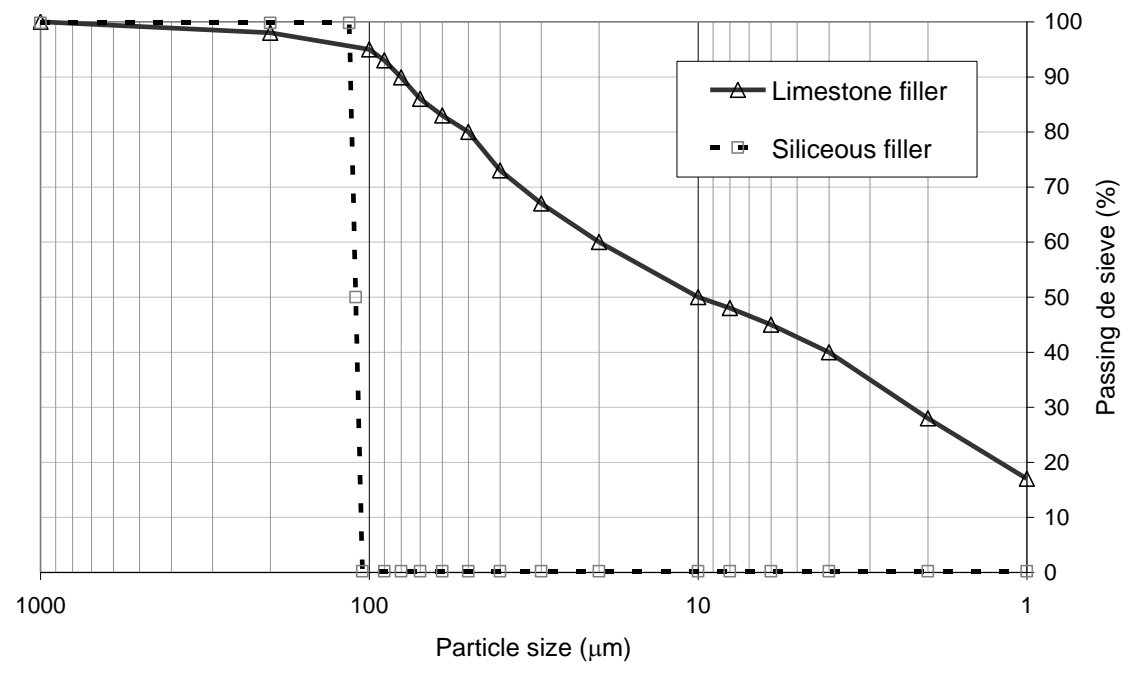

Fig. 2 Experimental setup for shrinkage and mass loss monitoring during early ages

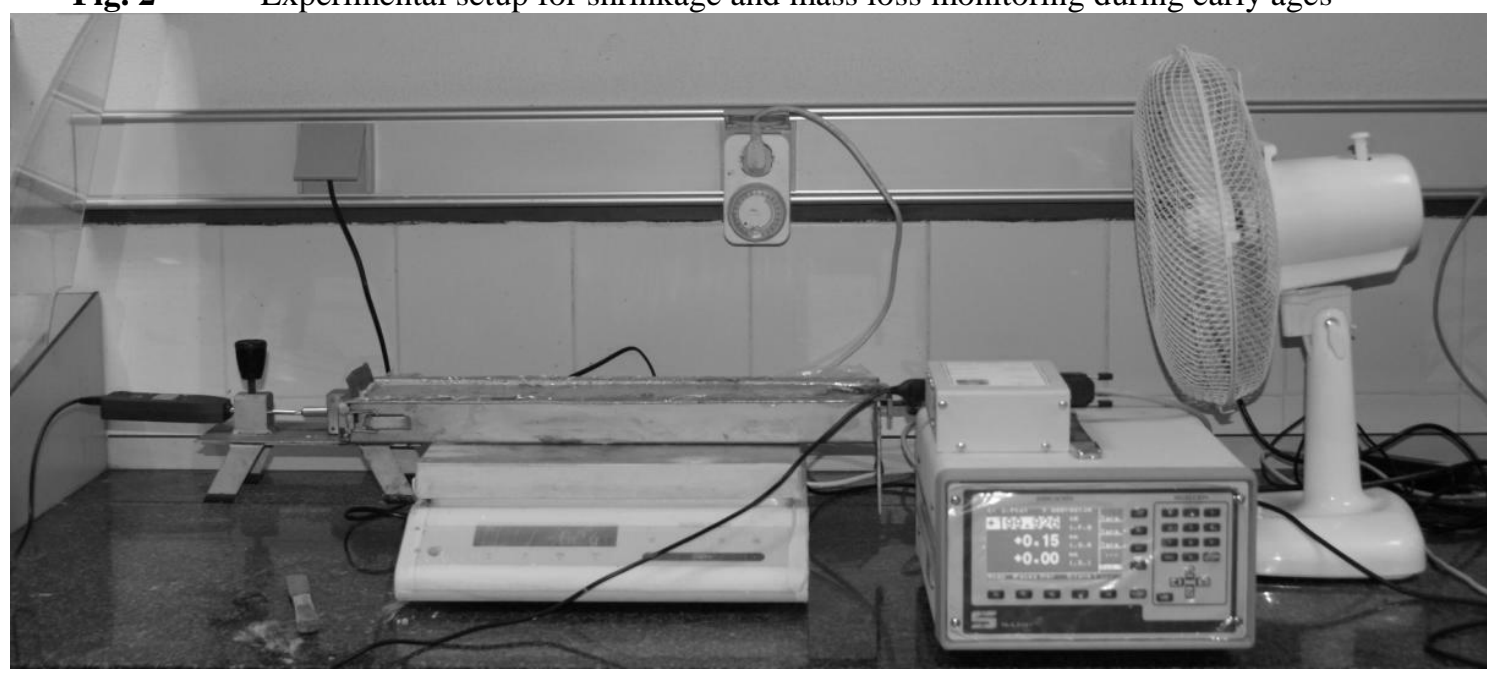

Fig. 3 Steel mould and experimental setup of the double restrained slab early age cracking test

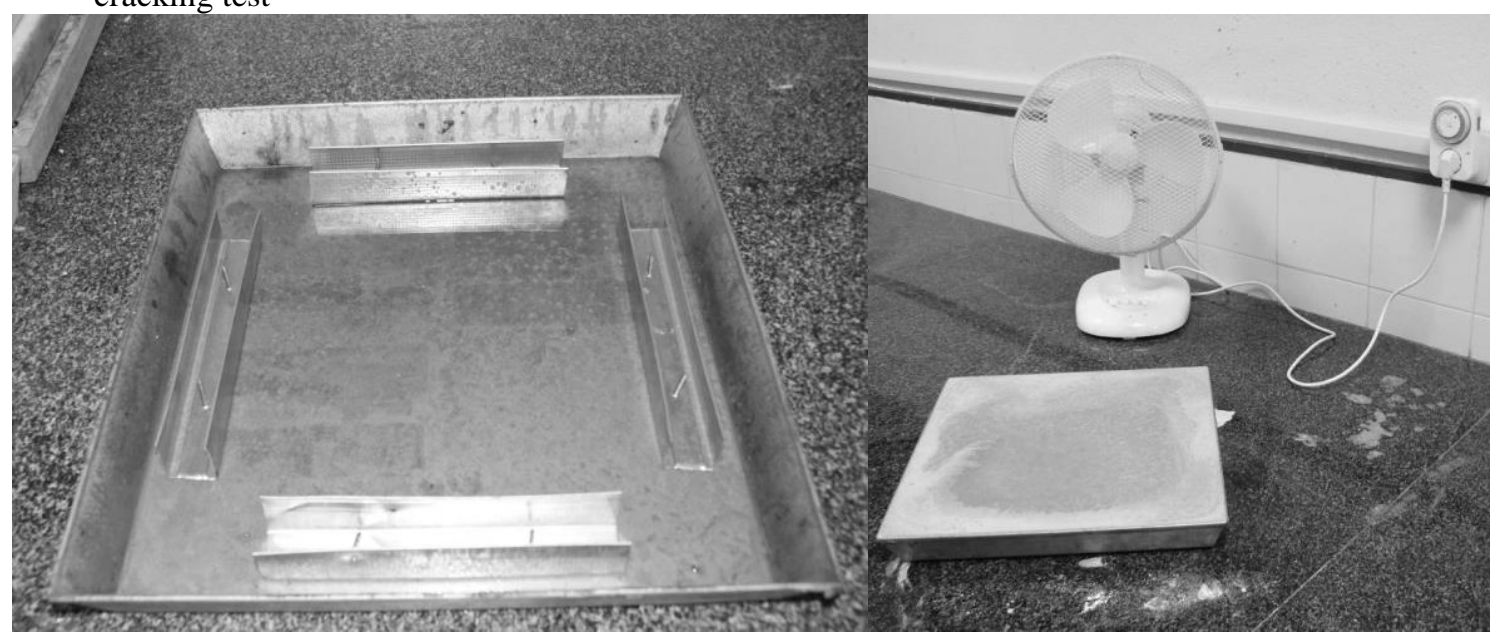


Fig. 4 Compressive strength of hardened samples with limestone (CA) and siliceous (SI) filler at 1, 7, 14 and 28 days. Results of Air cured and Water cured samples

CA
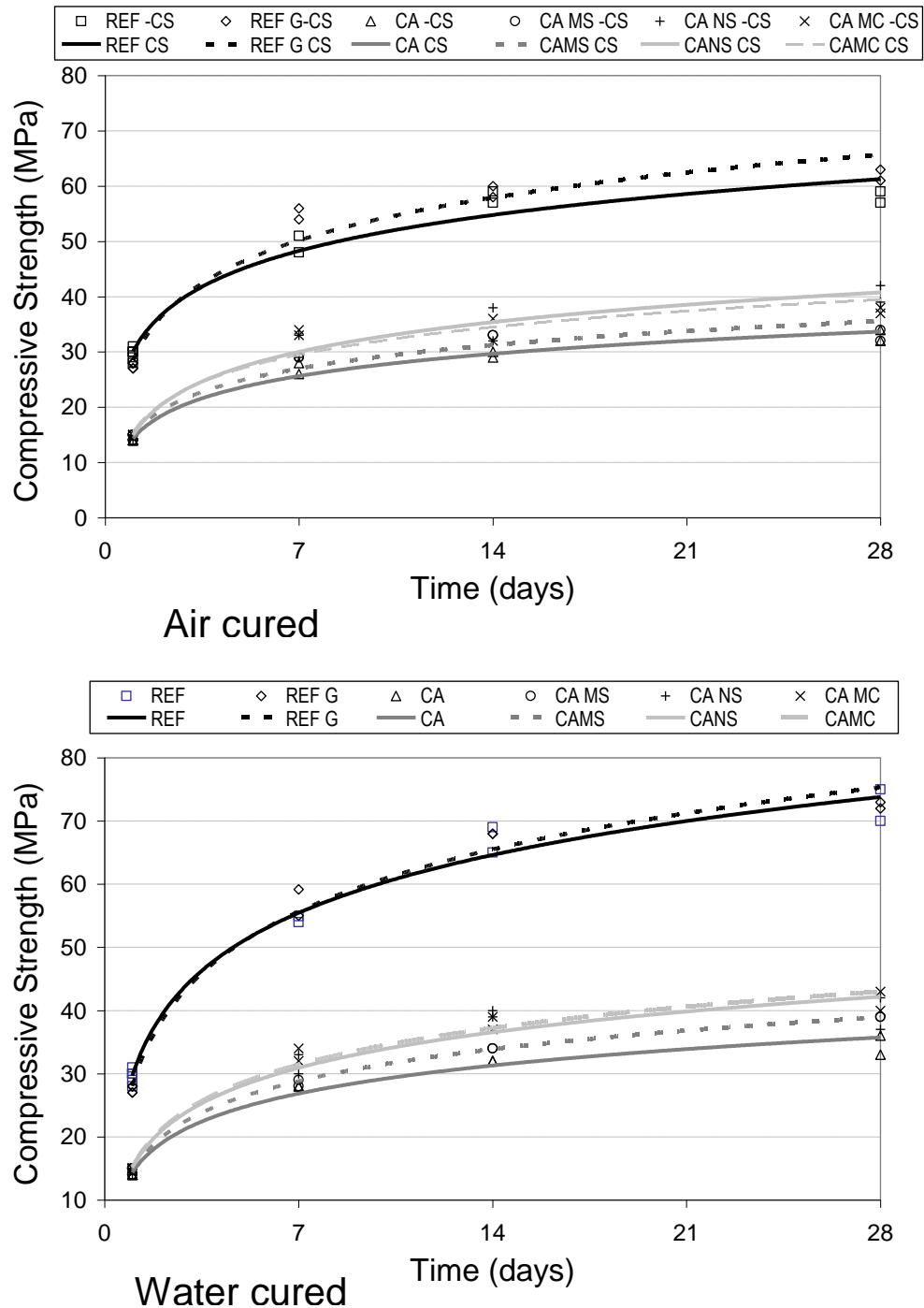
(Continued Figure 4)

\section{SI}
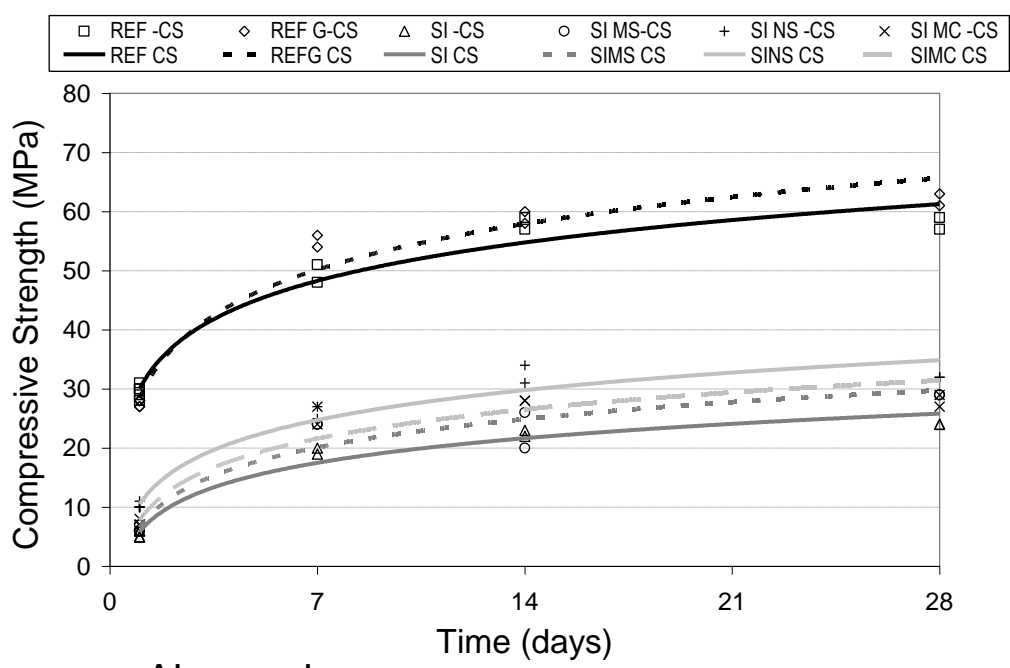

Air cured

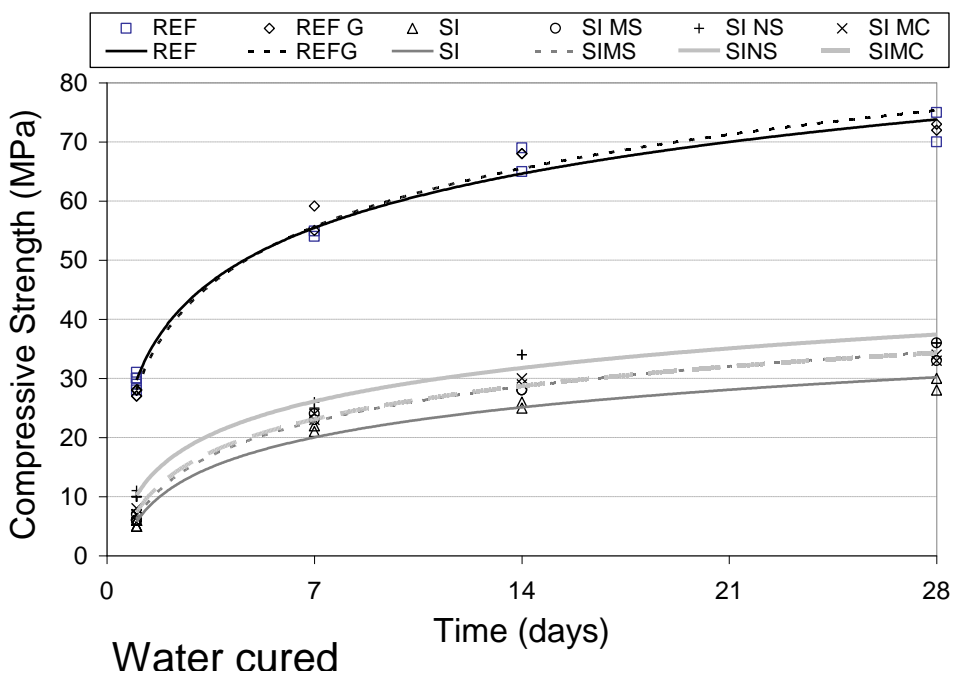


Fig. 5 Ultrasonic Pulse Velocity (UPV) of hardened samples with limestone (CA) and siliceous (SI) filler at 1, 7, 14 and 28 days. Results of Air cured and Water cured samples

CA
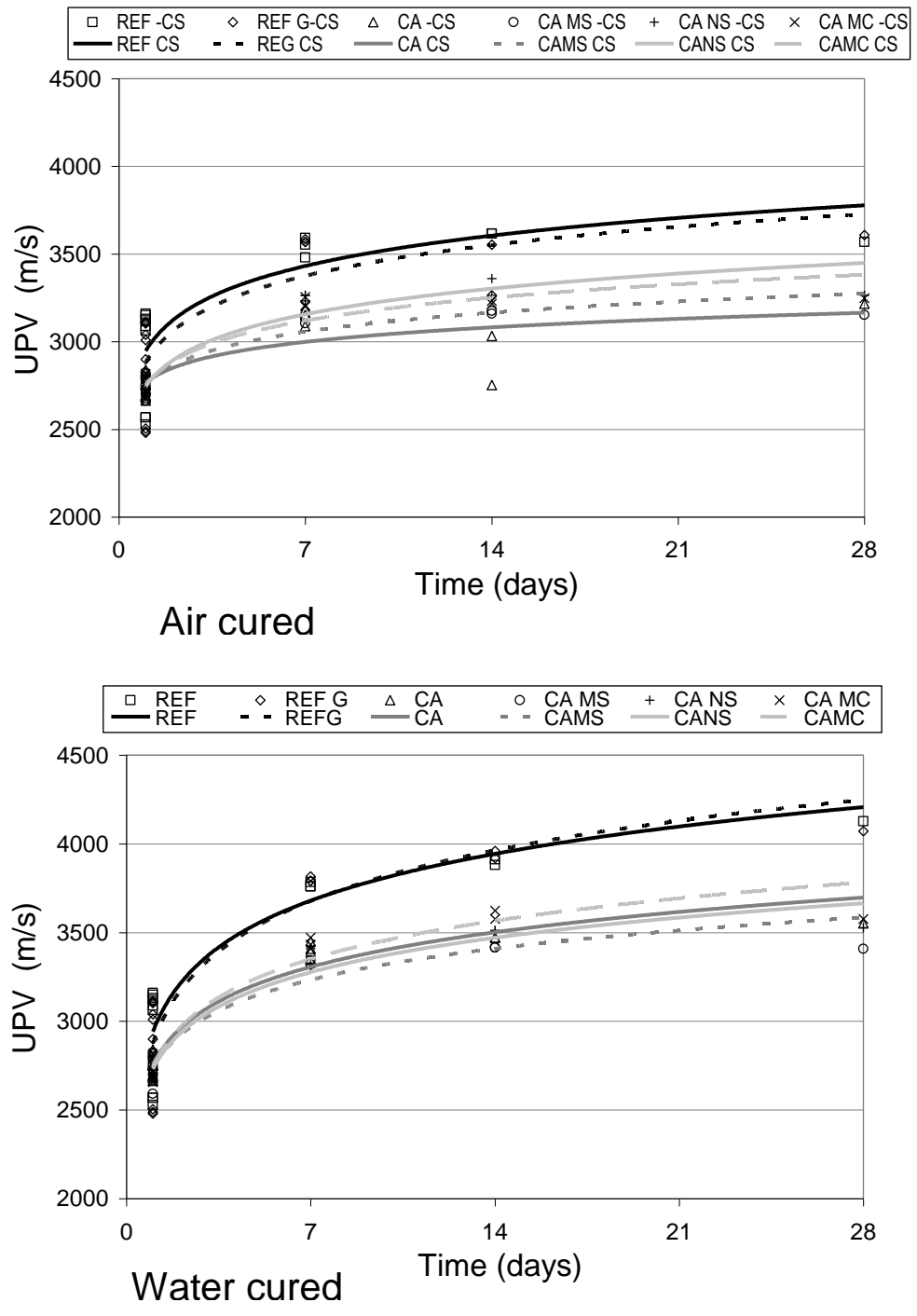


\section{(Continued Figure 5)}

\section{SI}

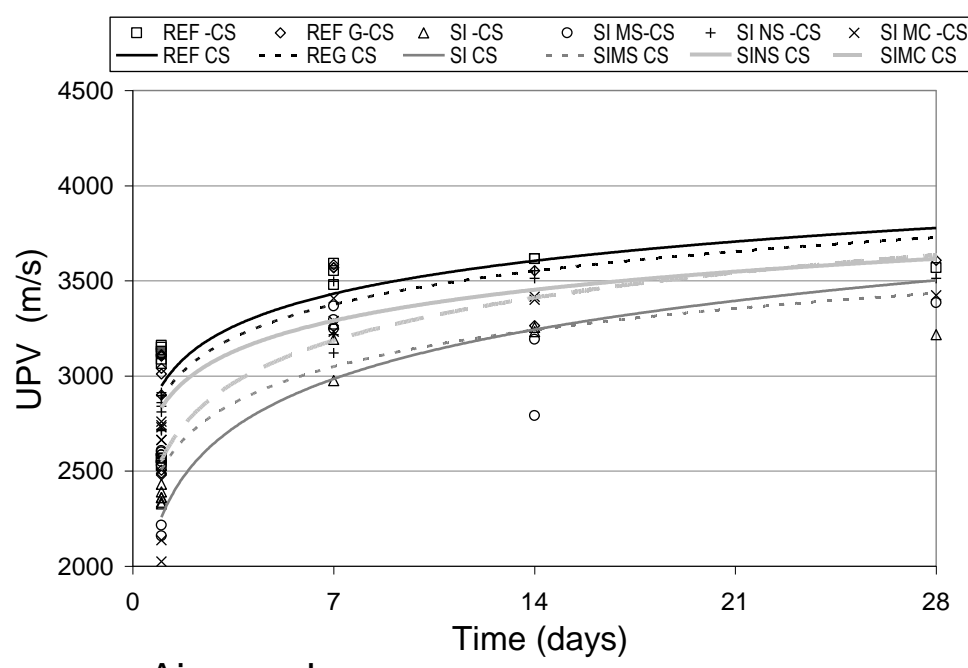

Air cured

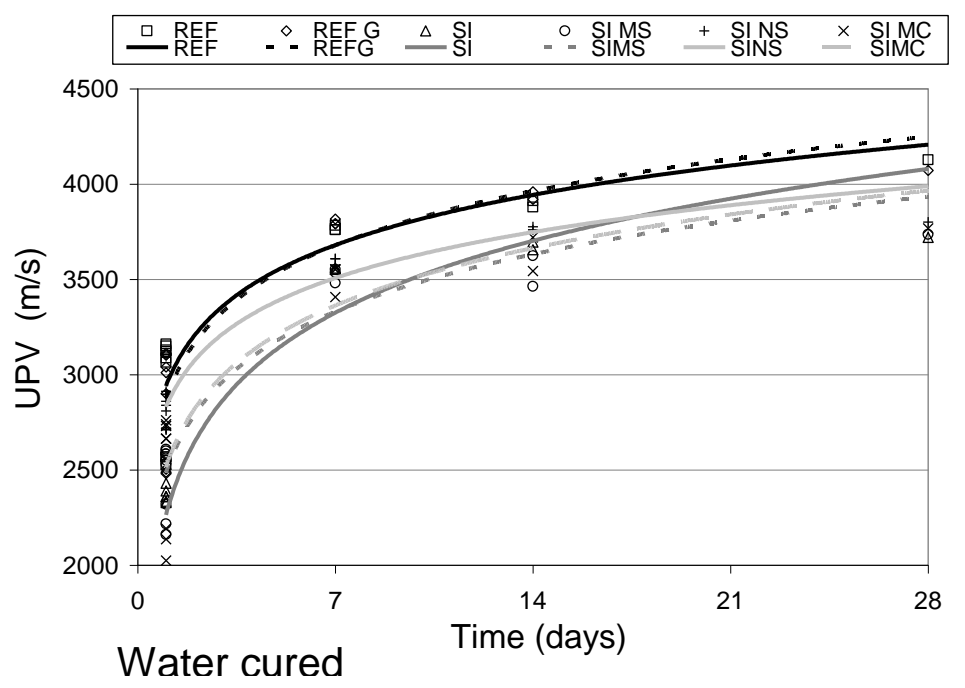


Fig. 6 Temperature during early ages in paste samples

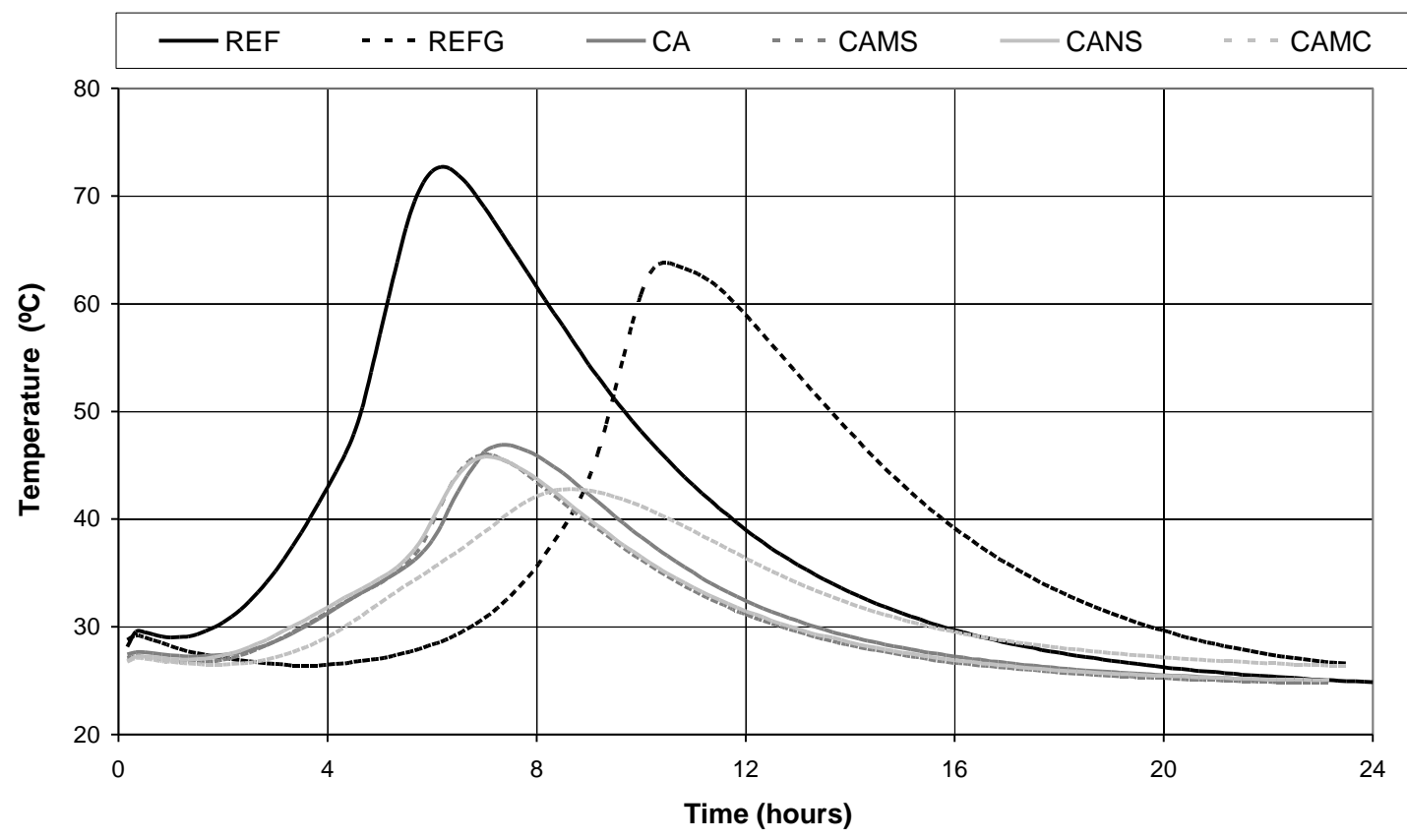

Fig. 7 Reaction degree of the pastes under study (up to 24 hours)

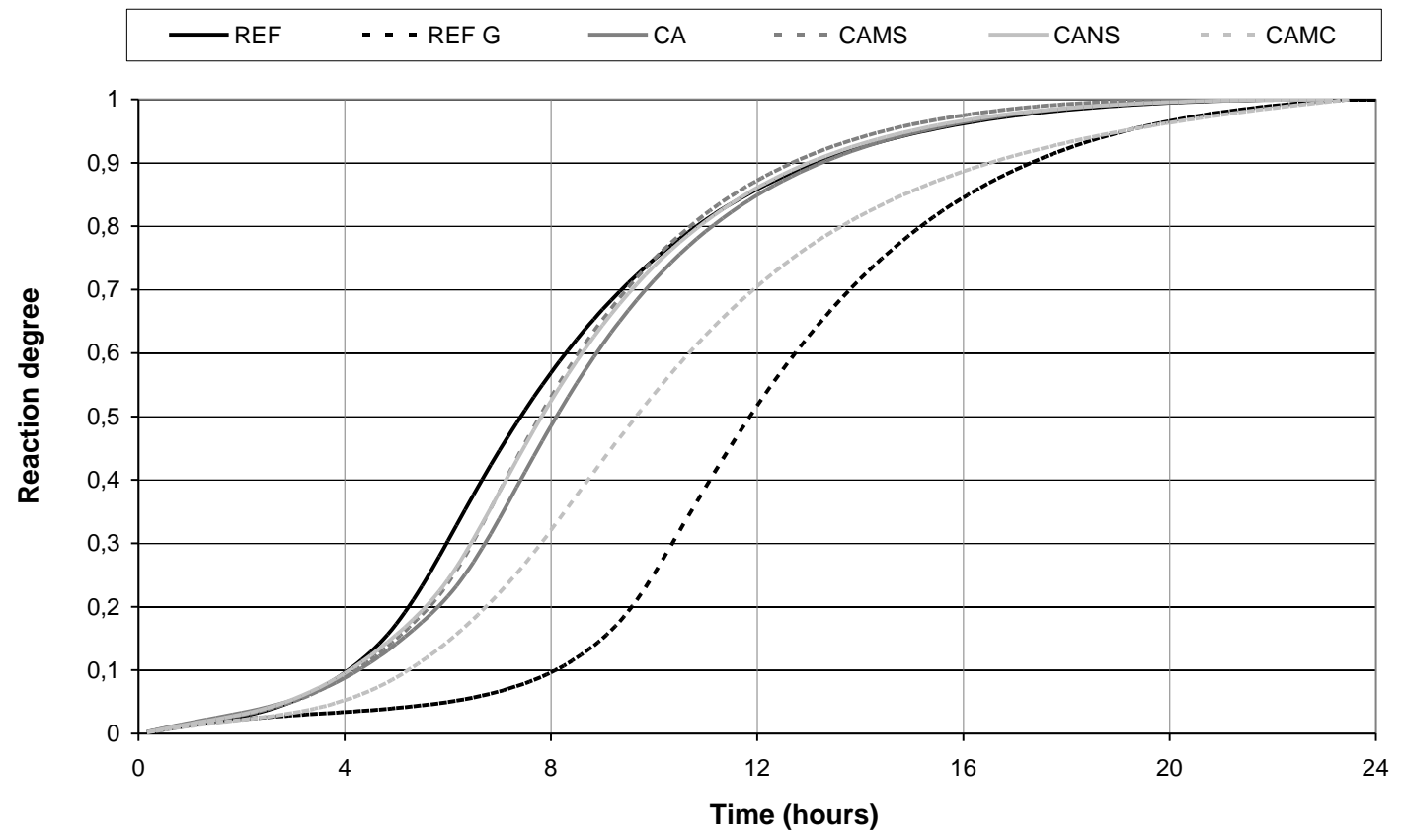


Fig. $8 \quad$ Ultrasonic pulse velocity (UPV) at early ages of paste samples

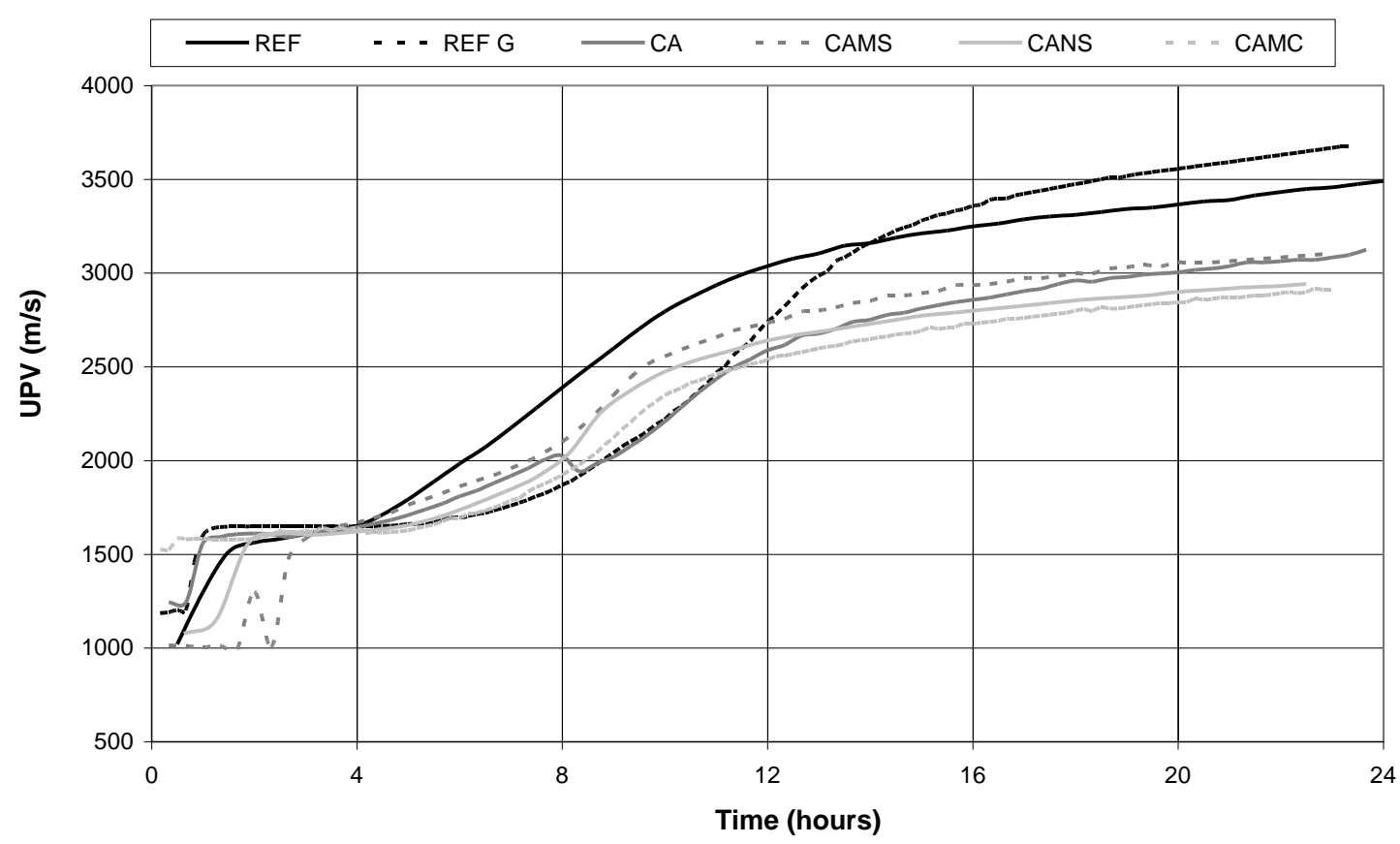

Fig. 9 UPV of fluid pastes related to in-situ temperature at early ages (up to 24 hours)

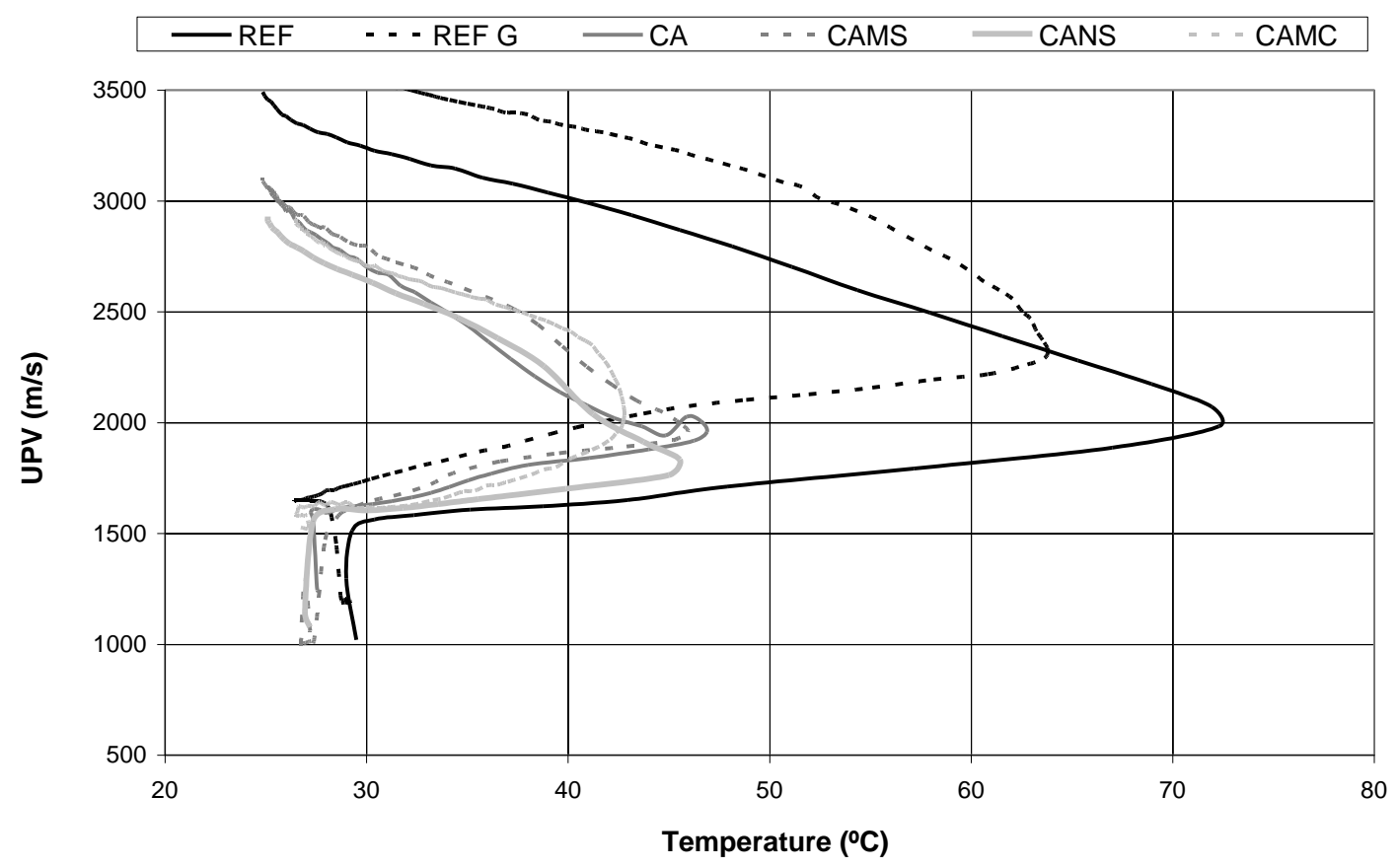


Fig. 10 Ultrasonic Pulse Velocity (UPV) of pastes at early ages related to reaction degree $\left(\mathrm{R}_{\mathrm{d}, 24}\right)$

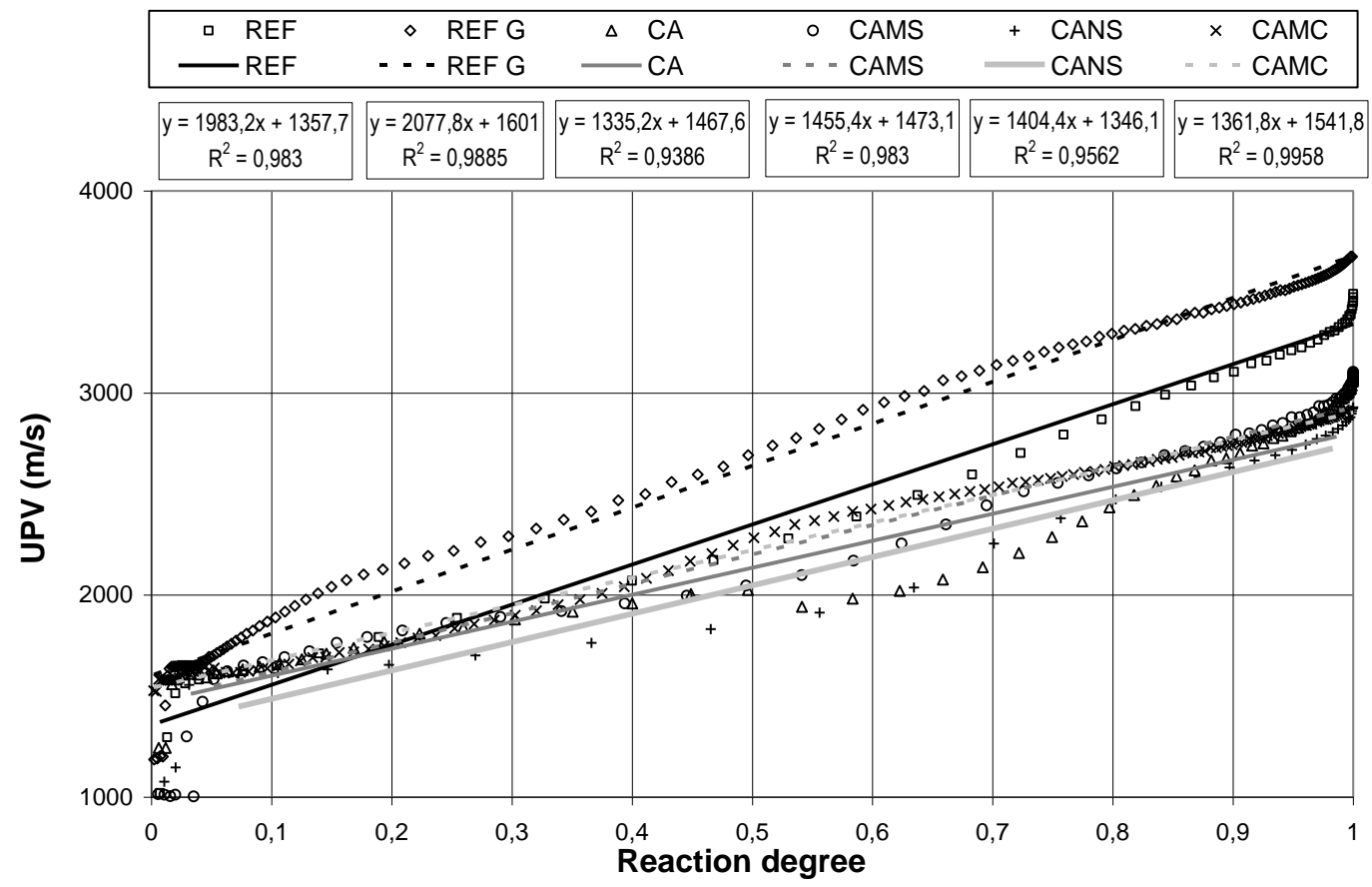

Fig. 11 Early age drying Shrinkage of paste samples with limestone filler with air flow $(3 \mathrm{~m} / \mathrm{s})$

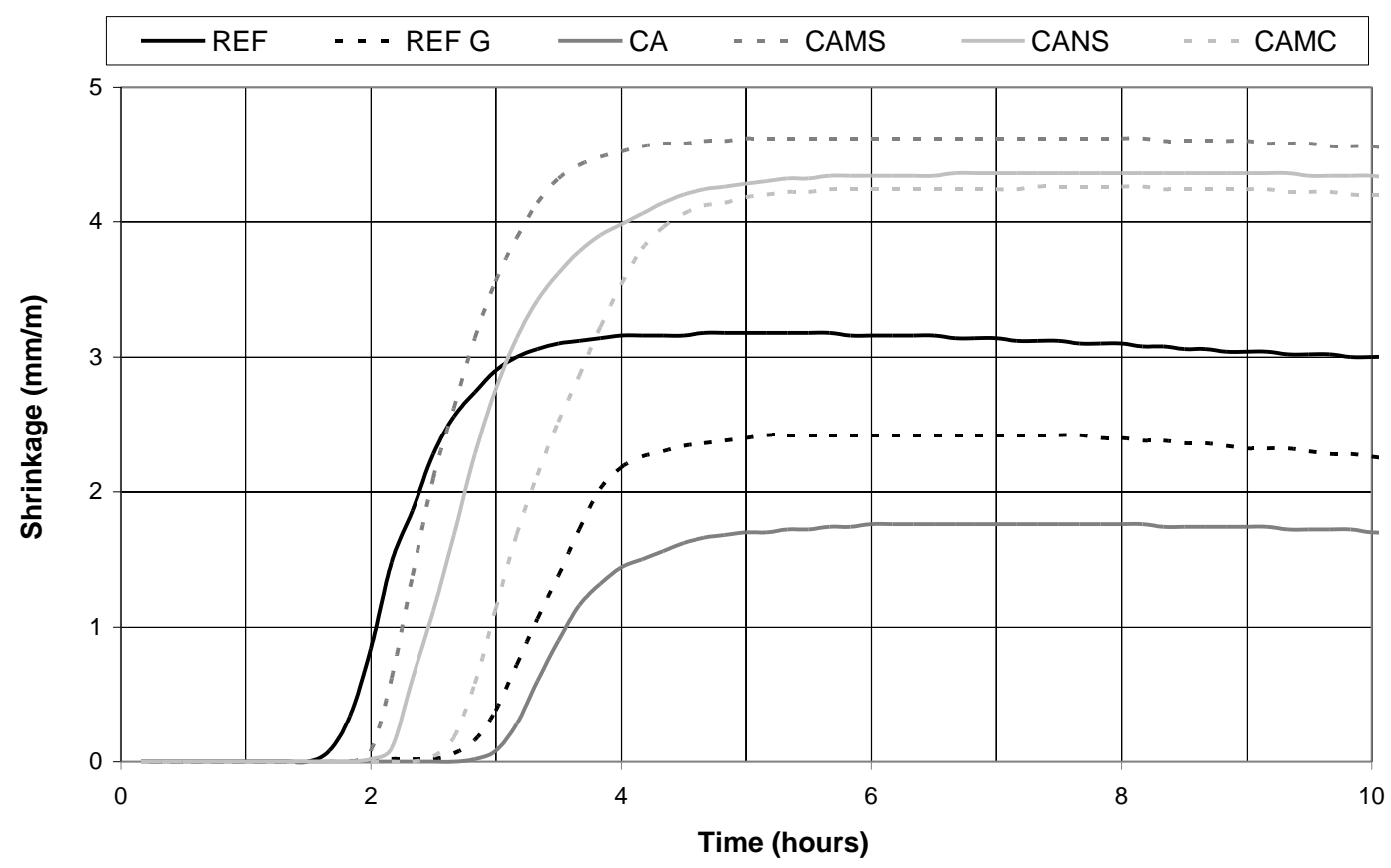


Fig. 12 Water evaporation on paste samples at early ages (first 6 hours after casting under $3 \mathrm{~m} / \mathrm{s}$ of air flow)

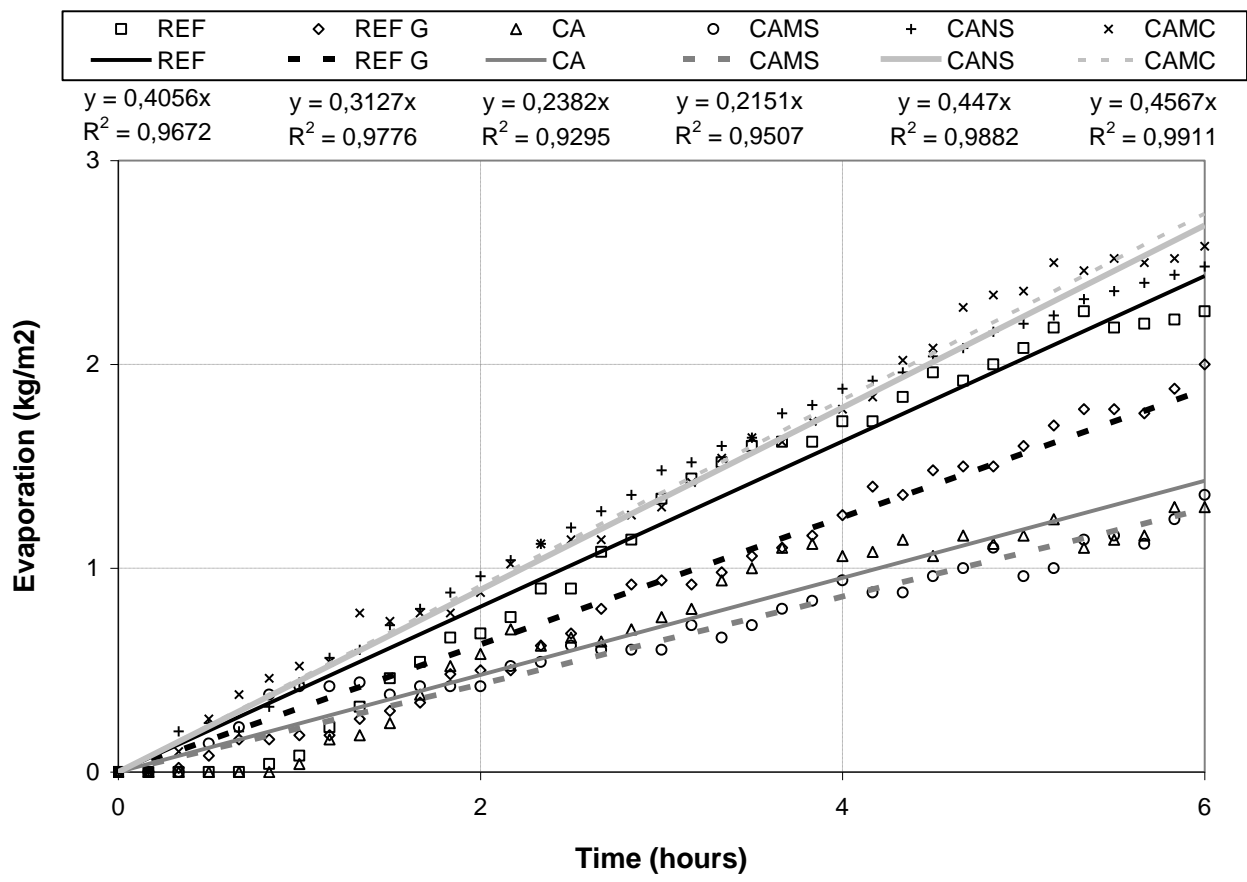

Fig. 13 Drying shrinkage and Evaporation during early age shrinkage development (approx. 2-4 hours)

\begin{tabular}{|c|c|c|c|c|c|}
\hline$\square$ REF & $-\diamond-$ REF G & $\triangle C A$ & $=0-$ CAMS & + CANS & $=X-$ CAMC \\
\hline $\begin{array}{c}y=4,3649 x-1,7776 \\
R^{2}=0,9271\end{array}$ & $\begin{array}{c}y=6,1603 x-4,8654 \\
R^{2}=0,9074\end{array}$ & $\begin{array}{c}y=3,3671 x-2,19 \\
R^{2}=0,9567\end{array}$ & $\begin{array}{c}y=15,045 x-6,1014 \\
R^{2}=0,9335\end{array}$ & $\begin{array}{c}y=4,725 x-4,0659 \\
R^{2}=0,9531\end{array}$ & $\begin{array}{c}y=5,0899 x-5,2623 \\
R^{2}=0,9768\end{array}$ \\
\hline
\end{tabular}

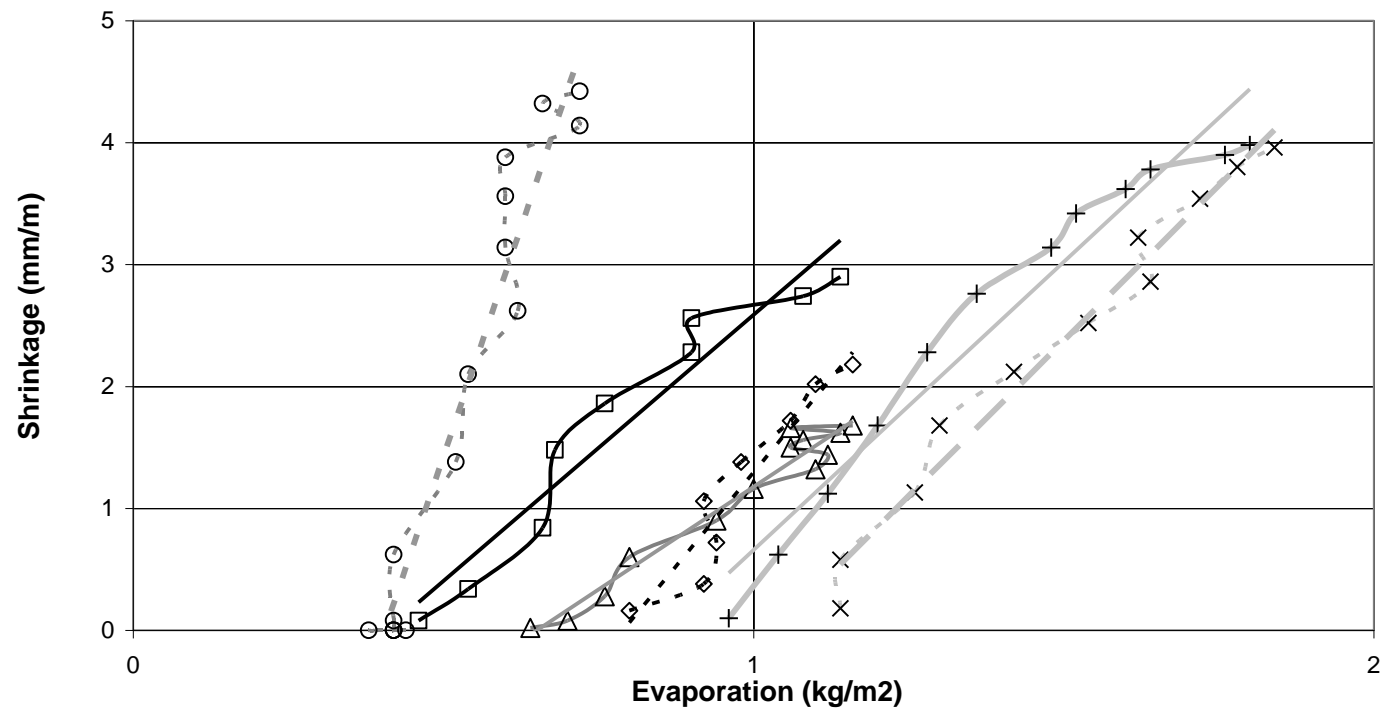


Fig. 14 Drying Shrinkage of pastes with related to reaction degree at very early ages

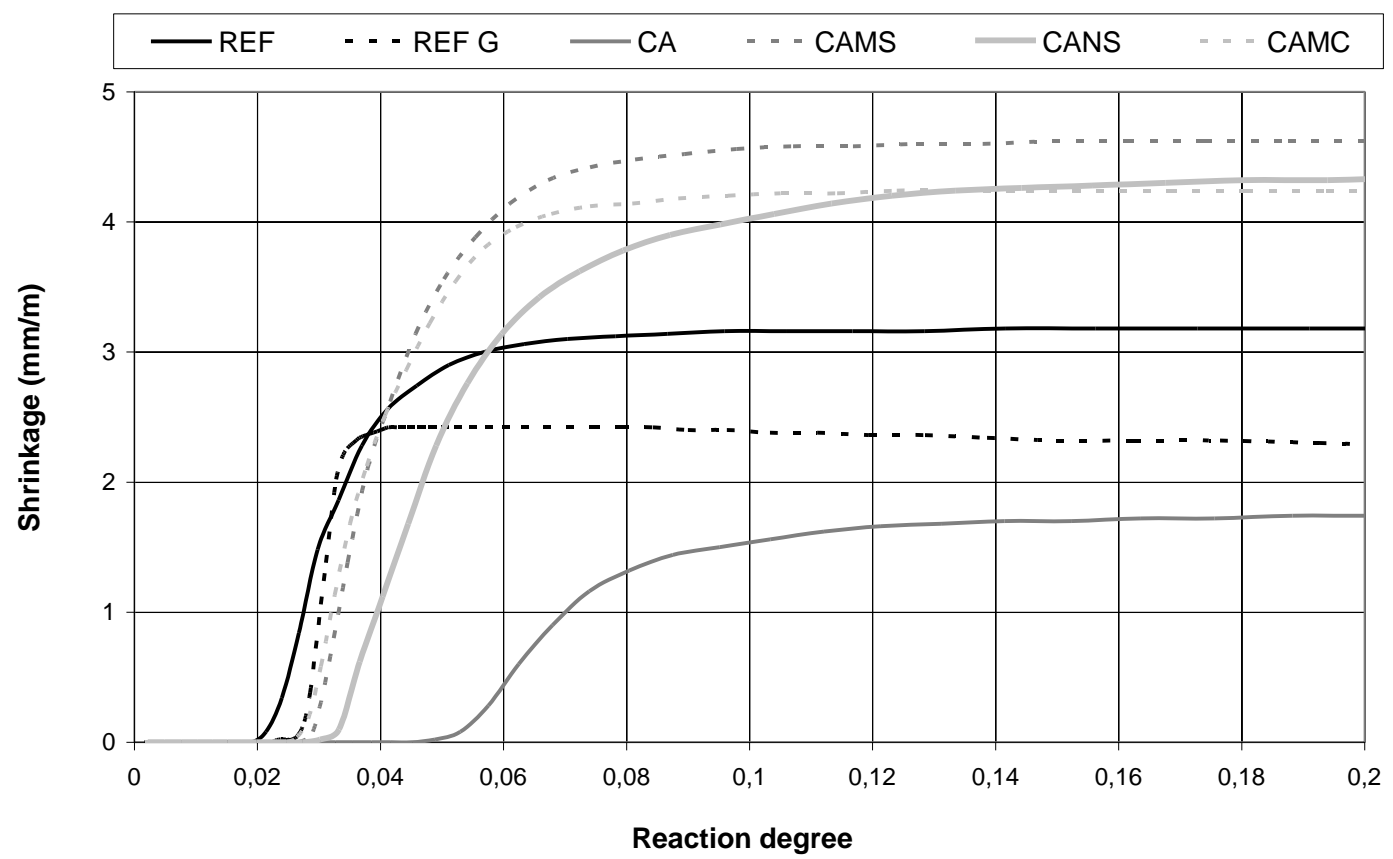

Fig. 15 Cracked area and maximum crack length measured on cracking test of limestone filler samples and reference pastes

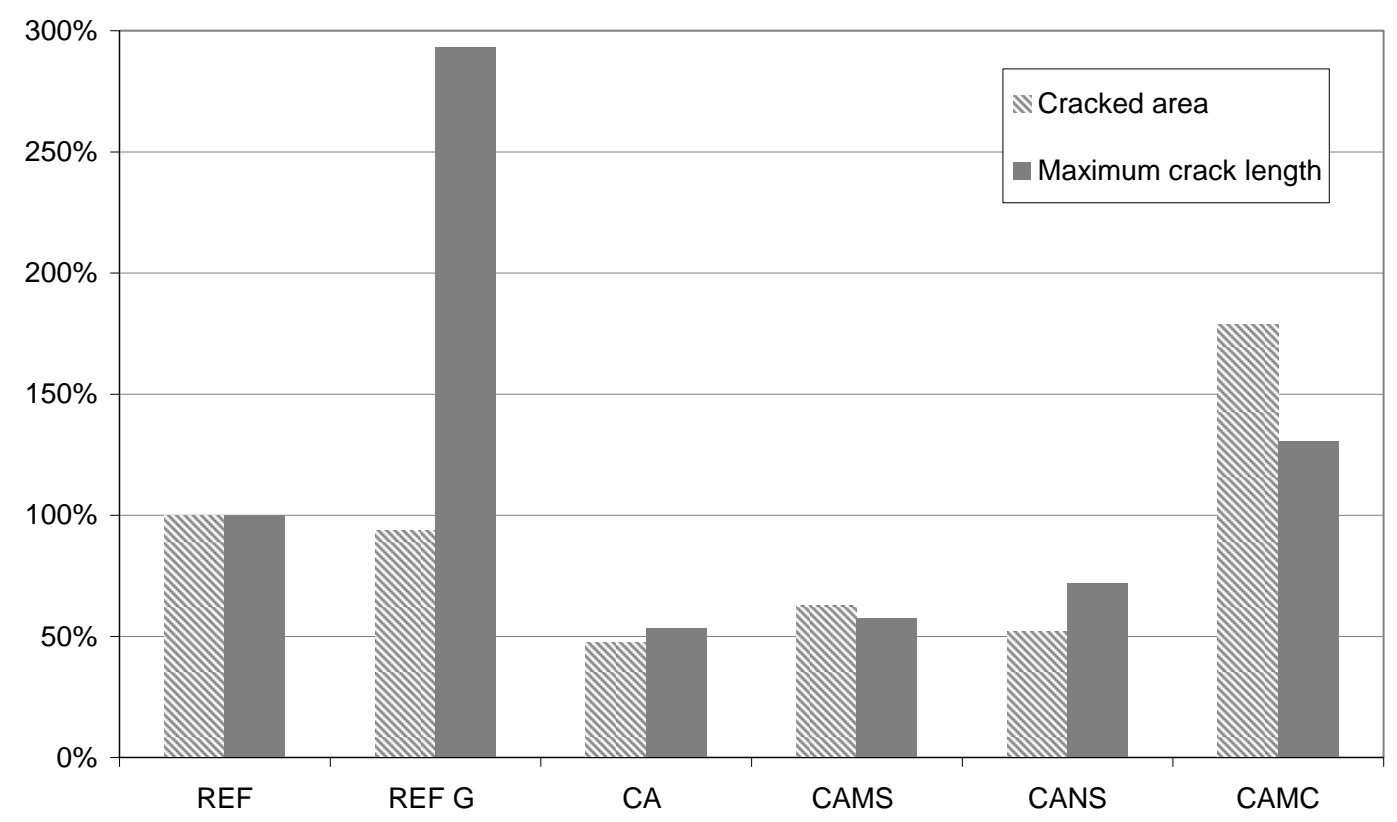


Fig. 16 Cracked samples with limestone filler and reference pastes after slab cracking test (dimensions 40 x $40 \mathrm{~cm}$ ). From left to right and downwards: REF, REF-G, CA, CAMC, CAMS and CANS

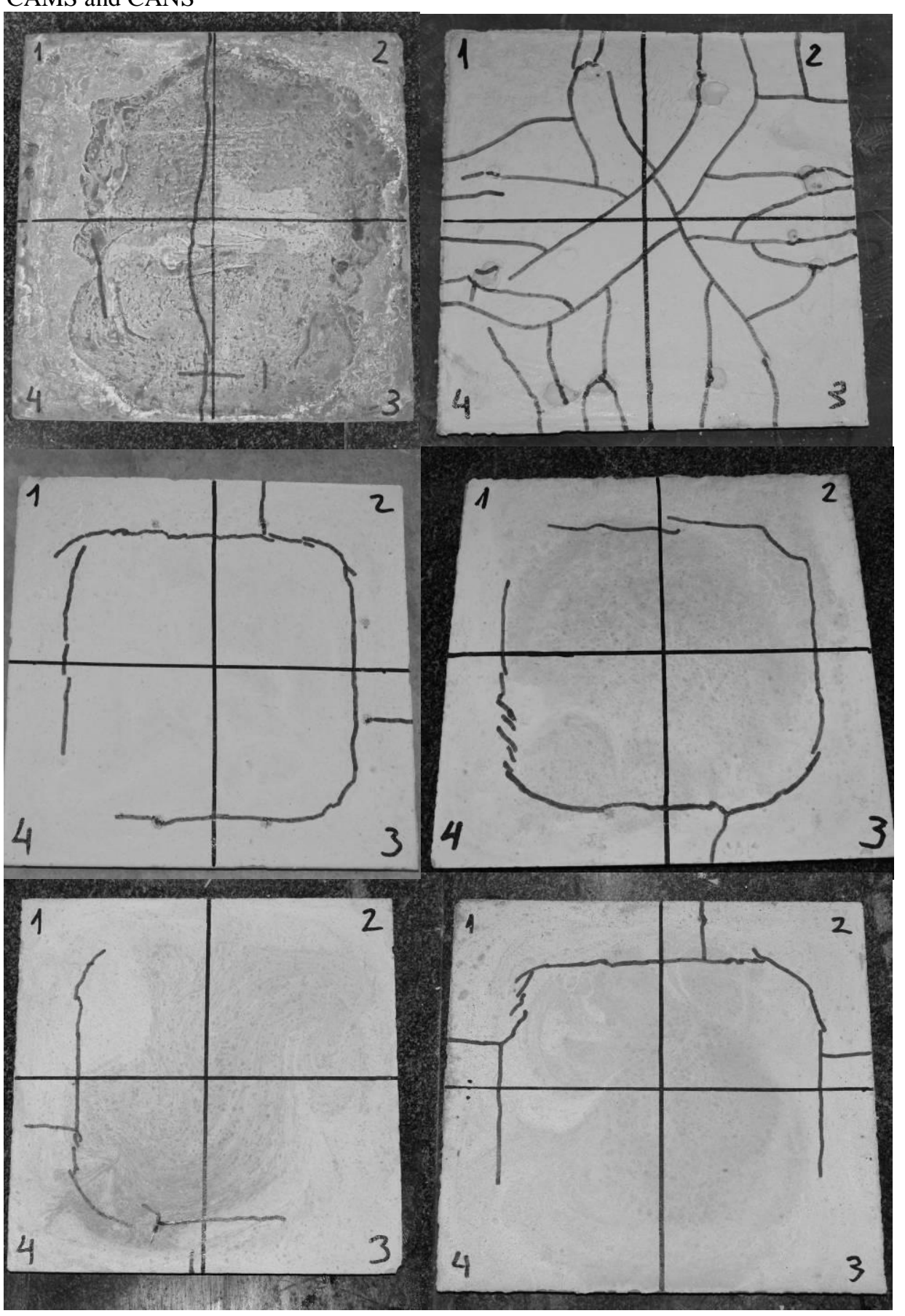


Fig. 17 Evolution and temporal relationships among key point early age parameters (temperature, UPV and shrinkage)

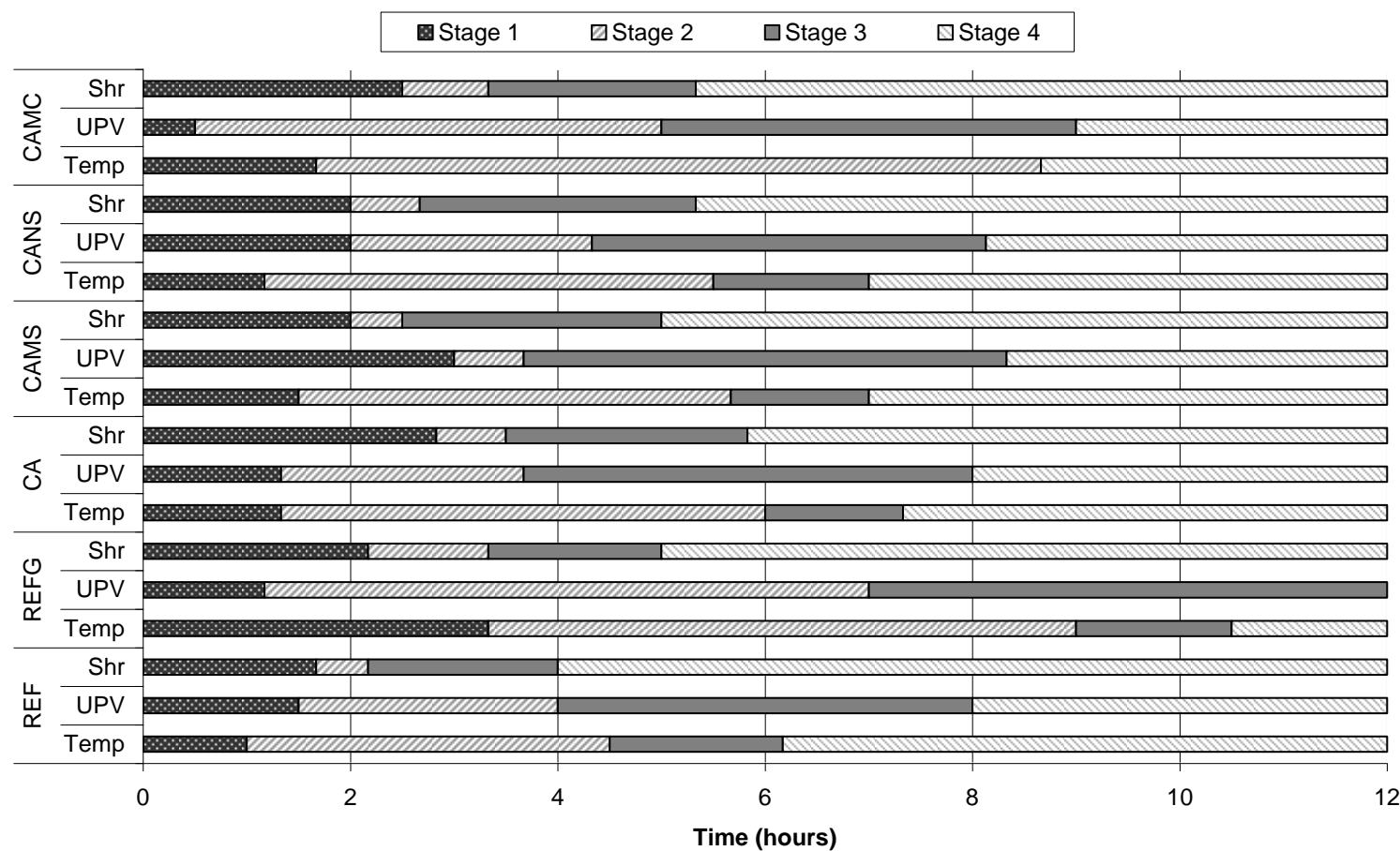

\begin{tabular}{|l|c|c|c|c|}
\hline Parameter & Stage 1 & Stage 2 & Stage 3 & Stage 4 \\
\hline Shrinkage & $\begin{array}{c}\text { Plastic State (no } \\
\text { shrinkage) }\end{array}$ & $\begin{array}{c}\text { Beginning until } \\
\text { knee point (fast } \\
\text { shrinkage) }\end{array}$ & $\begin{array}{c}\text { From knee point } \\
\text { until shrinkage } \\
\text { ending }\end{array}$ & $\begin{array}{c}\text { Hardened state } \\
\text { Slow shrinkage }\end{array}$ \\
\hline UPV & Unstable & $\begin{array}{c}\text { Landing (ca. } \\
1500-1600 \mathrm{~m} / \mathrm{s})\end{array}$ & $\begin{array}{c}\text { Accelerated } \\
\text { increase until } \\
\text { knee point }\end{array}$ & $\begin{array}{c}\text { Slow increase } \\
\text { and stabilization }\end{array}$ \\
\hline Temperature & $\begin{array}{c}\text { Minimum } \\
\text { reached }\end{array}$ & $\begin{array}{c}\text { Accelerated } \\
\text { increase }\end{array}$ & $\begin{array}{c}\text { Uniform increase } \\
\text { until maximum }\end{array}$ & $\begin{array}{c}\text { Temperature } \\
\text { decrease }\end{array}$ \\
\hline
\end{tabular}

